\title{
PRESIDENCIALISMO Y EL PODER PRESIDENCIAL EN EL PROCESO LEGISLATIVO CHILENO
}

\author{
PRESIDENTIALISM AND PRESIDENTIAL POWER IN THE CHILEAN \\ LEGISLATIVE PROCESS
}

\author{
Alan Bronfman Vargas*
}

\begin{abstract}
RESUMEN: A partir de la doctrina tradicional sobre la debilidad del presidencialismo como base de un régimen democrático este artículo expone una posible vía para entender los casos en que un presidencialismo exhibe un razonable funcionamiento como democracia. Un análisis de caso centrado en el poder colegislativo otorgado al Presidente de la República en Chile permite observar que sus facultades constitucionales no generan un poder decisorio exclusivo sobre la prioridad que tendrán los distintos proyectos de ley de su interés que se debatirán y votarán en el Congreso Nacional. Las normas y convenciones parlamentarias en lo procedimental generan un poder negociador favorable a los congresistas y que, por ende, fuerza al Presidente a generar consensos. En estos términos, el trabajo intenta esclarecer la posición relativa de Presidente y congresistas en la formación de la agenda legislativa.
\end{abstract}

Palabras clave: Presidencialismo, facultades legislativas, agenda legislativa.

ABSTRACT: From the traditional doctrine about the weakness of presidentialism as the basis of a democratic regime this paper presents a possible way to understand where a presidentialism exhibits a reasonably functioning as a democracy. A case study focused on the co-legislative powers granted to the President in Chile reveals that his constitutional powers not generate a unique decision-making power on the priority to have the various bills of interest to be discussed and voted on Congress. The rules and conventions in parliamentary procedural generate a favorable bargaining power to congressmen and thus force the President to build consensus. In these terms, the paper attempts to clarify the relative position of President and Congress in the agenda setting process.

Key words: Presidentialism, legislative powers, agenda setting.

\section{INTRODUCCIÓN}

Los estudios sobre el funcionamiento y reforma de los sistemas de gobierno presidencialistas en Iberoamérica con frecuencia contienen tres afirmaciones básicas. La primera es que el régimen presidencialista carece de aptitud para sustentar un sistema democrático estable. La segunda es que el presidencialismo entrega un poder excesivo al Presidente o bien, en el extremo opuesto, lo configura como una magistratura débil incapaz de imprimir coherencia al funcionamiento del régimen político. La tercera es que el parlamentarismo o

\footnotetext{
* Profesor de Derecho Constitucional de la Pontificia Universidad Católica de Valparaíso. Correspondencia a correo electrónico alan.bronfman@ucv.cl. El autor agradece a María Cristina Durrells la provisión de los datos del proceso legislativo que sustentan las afirmaciones expuestas en este artículo.
} 
el semipresidencialismo constituyen una mejor alternativa para la construcción de una democracia efectiva en Iberoamérica ${ }^{1}$.

En relación a la primera afirmación son varios los trabajos que sostienen que los presidencialismos tienen cierta propensión a generar un quiebre institucional. Juan Linz afirma que el presidencialismo crea mayores riesgos para una política democrática estable que el parlamentarismo y autores como Stepan, Skach, Cheibub, Riggs, Palmer y Valenzuela, entre otros, apoyan con datos dicha afirmación ${ }^{2}$. Stepan y Skach, en un estudio que comprende setenta y siete países, descubren que la democracia sobrevive $61 \%$ del tiempo en parlamentarismo y solo el $20 \%$ del tiempo en presidencialismos ${ }^{3}$. Cheibub, en un estudio de noventa y nueve democracias entre 1950 y 1990, observa que la expectativa de vida de la democracia bajo un presidencialismo es aproximadamente de veintiún años mientras que bajo un parlamentarismo es de setenta y tres años ${ }^{4}$. En la misma línea argumental, Riggs sostiene que desde 1945 treinta países del tercer mundo con constituciones presidencialistas han sufrido golpes de estado, sin que ninguno pueda exhibir una secuencia ininterrumpida de elecciones presidenciales y parlamentarias 5 . Este dato contrasta con los cuarenta y tres países del tercer mundo que han adoptado el parlamentarismo, de los cuales solo trece han sufrido un quiebre institucional. Arturo Valenzuela, citando a Scott Palmer, señala que entre 1930 y 1980, en los treinta y siete países de Latinoamérica se concretan doscientos setenta y siete cambios de gobierno de los cuales el 37,5\% tienen su origen en un golpe de estado militar ${ }^{6}$. El mismo autor observa que desde 1980, si bien la tasa de intervenciones militares decrece (en simetría con los cambios derivados del fin de la guerra fría), la interrupción y cese anticipado del mandato presidencial sigue siendo una cifra relevante en los presidencialismos americanos ${ }^{7}$.

Los problemas del presidencialismo para sostener un régimen democrático pueden explicarse siguiendo dos caminos. El primero es el que entiende que el problema tiene su origen en tres deficiencias estructurales o propias del diseño de todo presidencialismo: la rigidez temporal de los mandatos populares, la tendencia mayoritaria dominante en la pre-

\footnotetext{
1 A modo de ejemplo pueden citarse las obras y trabajos de Linz et al. (1990), Arriagada y Godoy (1992) y LARRAÍn (2014).

2 LinZ (1994) p. 70.

3 Los autores utilizan la escala de Gastil de derechos políticos para calificar como democráticos los sistemas políticos que al menos han funcionado un año entre 1973 y 1989 en tal calidad. De los setenta y siete países que superan esta exigencia, eliminan a veinticuatro que pertenecen a la OECD, para evitar la distorsión que podría significar la estabilidad económica como sustrato de la estabilidad política. STEPAN y SKACH (1993) p. 10.

4 Cheibub (2002) p. 132. En un estudio posterior, que comprende el período 1946-2002, la expectativa de vida del presidencialismo sube a veinticuatro años y la del parlamentarismo baja a cincuenta y ocho años; CHEIBUв (2007) p. 136.

5 RigGs (2004) pp. 218 y 219.

6 Valenzuela (2004) p. 5.

7 Valenzuela cita los casos de cese anticipado de Hernán Siles Suazo (Bolivia, 1985), Bertrand Aristide (Haití, 1991 y 2004), Raúl Alfonsín (Argentina, 1989), Joaquín Balaguer (República Dominicana, 1996), Abdalá Bucaram (Ecuador, 1997), Fernando Collor de Mello (Brasil, 1992), Raúl Cubas (Paraguay, 1999), Jorge Serrano (Guatemala, 1993), Alberto Fujimori (Perú, 2000), Jamil Mahuad (Ecuador, 2000), Carlos Andrés Pérez (Venezuela, 1993), Fernando de la Rúa (Argentina, 2001), Gonzalo Sánchez de Losada (Bolivia, 2003). Valenzuela (2004) pp. 7-9.
} 
sidencia, y la legitimidad democrática dual ${ }^{8}$. Estos tres elementos condicionarían de modo significativo la relación entre el Presidente y la Asamblea, generando una tensión confrontacional que incentiva el mutuo bloqueo entre poderes.

El segundo, junto con subrayar la dificultad de comparar regímenes políticos con historia, instituciones y economía diferentes, sostiene que el problema no surge exclusivamente de condiciones estructurales sino más bien de disposiciones particulares que incentivan o desincentivan la colaboración de poderes ${ }^{9}$. El mérito de esta tesis es que permite dar cuenta del funcionamiento de algunos presidencialismos más allá de la supervivencia democrática fundada en factores coyunturales históricos y políticos vinculados al sistema electoral y al sistema de partidos que este propicia.

Las dos tesis señaladas constituyen la puerta de entrada al análisis particular de cualquier aspecto del funcionamiento del presidencialismo. Si se acoge la primera explicación, el estudio particular ha de insertarse en la lógica de los defectos estructurales, para entender su sentido en el funcionamiento de la democracia. Si se acoge la segunda explicación, el estudio particular de disposiciones esenciales del presidencialismo podría descubrir defectos pero también méritos en su incidencia sobre el régimen democrático. Sin perjuicio que el trabajo discurrirá sobre la base de esta segunda mirada, expondremos los elementos centrales de la primera tesis.

\section{LOS PROBLEMAS ESTRUCTURALES DEL PRESIDENCIALISMO}

Según la doctrina, las tres deficiencias estructurales de todo presidencialismo son la rigidez temporal de los mandatos populares, la tendencia mayoritaria dominante en la presidencia, y la legitimidad democrática dual. Explicaremos brevemente estas tres deficiencias.

El carácter fijo de la extensión de los mandatos populares del Presidente y congresistas no ofrece una respuesta satisfactoria al conflicto político que puede suscitar una mayoría parlamentaria contraria al Poder Ejecutivo. La única posibilidad de adelantar el término de un mandato en el régimen presidencialista es la destitución del Presidente por medio de un juicio constitucional, pero se trata de un camino que exige una mayoría reforzada en el Congreso y la existencia de conductas que puedan relacionarse con las causales de acusación previstas en la Constitución.

La rigidez de los mandatos tiene un componente externo adicional ya que incluso en aquellos casos en que el sistema político es capaz de elegir a un Presidente popular y competente, el presidencialismo en Iberoamérica tiende a acotar su mandato a un período me-

\footnotetext{
8 Linz (1994) p. 6-22; Lijphart (1994) pp. 92-93, 101-103; Chasquetti (2001) pp. 319-320; Gamboa (2005) p. 60; Shugart y Carey (2009) p. 27.

9 El forzoso estudio de las disposiciones particulares que regulan el funcionamiento de las atribuciones que configuran la relación entre Poder Ejecutivo y Poder Legislativo es indicado por autores con distintos tonos y matices, con frecuencia destacando la relevancia de la cooperación: Thibaut (1998) p. 147, NohLEN (1998B) pp. 17, 18 y 24, Monsalve y Sottoli (1998) pp. 44 y 49, Cheibub y Limongi (2000) p. 152; Alcántara y Sánchez (2001) p. 60-63, Chasquetti (2001) pp. 340-341, Morgenstern (2002) pp. 437-441, Berríos y Gamboa (2006) pp. 100-101; Alemán y SChWARTZ (2006) pp. 115-117. Nohlen lo entiende importante como respuesta a lo que denomina el espejismo de las (malas) estadísticas del presidencialismo, NoHLEN (1998C) pp. 87 y 88.
} 
diante la prohibición de reelección inmediata ${ }^{10}$. Esto fuerza la búsqueda de un nuevo líder político, partidista y social, cada cuatro o cinco años, lo que no resulta sencillo en ninguna comunidad política. De hecho, es posible observar una explicable y recurrente tentación de reutilizar el liderazgo comprobado de un anterior Presidente en un nuevo período presidencial no consecutivo.

La tendencia mayoritaria del presidencialismo deriva del carácter unipersonal de la magistratura presidencial, que propicia que solo una doctrina, ideología o partido político disponga de un conjunto de herramientas privilegiadas para adoptar decisiones que afectan a toda la sociedad. El problema estriba en que la doctrina, ideología o partido político que encarna el Presidente puede ser minoritario en la sociedad y en la Asamblea y, por lo mismo, el Presidente puede ser incapaz de promover con éxito los cambios comprometidos en su programa de gobierno y que le permitieron acceder al poder. Esta situación genera una tensión institucional de envergadura, pues enfrenta a un Presidente que goza de una legitimidad democrática con una Asamblea que no quiere renunciar a su representación popular y ni a la defensa de sus propios intereses políticos y electorales.

La doctrina sostiene que este rasgo del presidencialismo distorsiona la precisión de la representación en el sistema político y contribuye al extremismo político ${ }^{11}$. Como el ganador gana el cien por ciento de la representación, pues hay un solo cargo en disputa, la desviación de la proporcionalidad será siempre el cien por ciento menos el porcentaje de votación obtenido por el ganador. Si es una elección con múltiples candidatos, la desviación será sesenta o más por ciento y si solo son dos, rara vez será menor del cuarenta por ciento. El resultado es siempre que el Presidente solo representa, con fidelidad, a una minoría de votantes. Este rasgo se proyecta sobre los ministros de Estado quienes responden al propio Presidente, pese a que el sistema de partidos y la composición de las bancadas parlamentarias induzcan y generen compromisos con los bloques o sectores afines al gobierno. La capacidad de los ministros de representar intereses minoritarios, como han sostenido Lijphart y Rogowski, queda subordinada al interés del Presidente por avanzar en su propia agenda y, por esta razón, la aptitud del presidencialismo para abordar problemas que atañen a minorías es más bien escasa ${ }^{12}$. El origen del problema parece ser la desproporcionalidad en la representación dentro del Poder Ejecutivo, pues el Presidente, aunque represente o encabece una fuerza política minoritaria, es el Jefe de Gobierno elegido por votación popular y tiene la facultad constitucional de remover a los ministros. Luego, la formación de consenso entre quienes se ubican en distintos niveles de poder es más difícil que aquella que tiene lugar en un régimen parlamentarista, donde se asume que el cargo de Jefe de Gobierno corresponde a un primus inter pares. El predominio del Presidente dentro del Poder Ejecutivo

10 En Iberoamérica prohíben toda reelección Honduras, Guatemala, México y Paraguay. La reelección presidencial inmediata está prohibida en Chile, Costa Rica, El Salvador, Panamá, Perú, República Dominicana y Uruguay. Por otro lado, hay países que permiten la reelección inmediata pero limitan la reelección subsecuente: Argentina, Bolivia, Brasil, Colombia y Ecuador. Estados Unidos permite la reelección inmediata pero no un tercer período consecutivo.

11 Shugart y Carey (2009) p. 30.

12 Lijphart y Rogowski (1993) p. 305. 
genera una falsa sensación de mandato popular, que da origen a una noción desproporcionada del apoyo al programa presidencial y del carácter inevitable de su implementación ${ }^{13}$.

La lógica de predominio de la voluntad presidencial en el seno del Poder Ejecutivo refuerza el interés de los partidos políticos por ganar la elección de Presidente y obtener la primacía en el sistema por todo un período. Quien ganó o contribuyó a ganar el poder espera avanzar en la consecución de sus intereses políticos mediante la implementación del programa político presidencial; quienes perdieron carecen de estímulos para cooperar con el ganador.

Finalmente, la doble legitimidad democrática del presidencialismo permite a los dos poderes elegidos por votación popular fundar, de manera separada y competitiva, sus pretensiones, intereses y decisiones políticas. La cooperación entre Presidente y Asamblea no es incentivada por el diseño institucional y, en períodos próximos a la elección, resulta más bien dificultada por el régimen presidencialista. La pervivencia del Poder Ejecutivo no depende de construir o mantener una mayoría en el parlamento, sin perjuicio que el progreso en el programa legislativo del gobierno exige contar con el apoyo de la mayoría de los congresistas de cada cámara. Si el Presidente carece de mayoría en la Asamblea, podría avanzar poco a poco con incentivos particulares dirigidos a la cooperación de los congresistas individuales que generan la mayoría. Si, por el contrario, el Presidente cuenta con dicha mayoría, la ausencia de una necesidad de apoyo permanente tiende a generar cierta insensibilidad presidencial ante las demandas de los parlamentarios, lo que alimenta una potencial crisis política. Esta insensibilidad se incrementa en aquellos casos en que el Presidente carece de experiencia parlamentaria y política, y tiene éxito electoral solo por su popularidad y atractivo para los votantes ${ }^{14}$.

La legitimidad democrática dual no genera incentivos para que los congresistas apoyen el programa legislativo del Presidente. Para los integrantes de las bancadas de oposición: no hay nada que ganar con la cooperación con el Poder Ejecutivo. El problema es que esta ausencia de incentivos también afecta a los congresistas que apoyan al gobierno, en especial, en aquellos sistemas en que el Presidente no puede ser reelecto. Aunque quieran que su partido continúe en el poder, la elección del nuevo candidato es una cuestión distinta que el apoyo al Presidente saliente. Este último no tiene ninguna elección por delante, a diferencia de los congresistas que buscan la reelección. Si el Presidente saliente ha perdido popularidad, resulta lógico que los congresistas busquen alejarse de su futuro político.

\section{LOS PROBLEMAS ESTRUCTURALES Y EL FUNCIONAMIENTO DEL PRESIDENCIALISMO}

Los tres problemas indicados no explican por completo el mal resultado exhibido por el presidencialismo como orden institucional de la democracia, ni sirven para entender su buen o satisfactorio rendimiento. Incluso hay quienes, como Cheihub, sostienen que la tesis del diseño institucional defectuoso no explica dicho rendimiento y que más bien son

13 Blondel y SuÁrez (1981) pp. 63-65.

14 Blondel y Suárez (1981) pp. 63-65. 
las condiciones en que las democracias presidencialistas existen las determinantes para su supervivencia ${ }^{15}$.

Ahora bien, sin cuestionar la sensible incidencia de los defectos estructurales en el funcionamiento de todos los presidencialismos, es posible comprobar que estos tienen un rendimiento distinto en términos de su capacidad de sustentar un régimen democrático efectivo. Esto es: pese a sus problemas, el presidencialismo ha demostrado, en algunos países, su aptitud para mantener una democracia operativa e incluso enfrentar circunstancias políticas en extremo adversas.

Entendemos que uno de los países en que el presidencialismo ha logrado mantener en funcionamiento el sistema democrático ha sido Chile. Puede afirmarse que el presidencialismo chileno, pese a las extendidas críticas formuladas a los poderes constitucionales otorgados al Presidente de la República, ha soportado con éxito veinticinco años de democracia, entendida esta, al menos, como un estándar básico de operación ${ }^{16}$. La democracia chilena de modo regular es reconocida como una buena democracia en términos comparativos y así se comprueba en algunos índices que intentan medir su calidad ${ }^{17}$.

Si se admite como premisa el buen o satisfactorio funcionamiento de la democracia chilena, este buen funcionamiento debiese apoyarse, en lo institucional, en la primacía del Presidente de la República sobre el Congreso Nacional en el ejercicio de la potestad legislativa. La fortaleza de las atribuciones presidenciales previstas por la Constitución debiese generar cierta primacía sobre el Congreso Nacional y tal primacía debiese explicar el rendimiento de nuestro régimen democrático. Sin embargo, esta forma de relación PresidenteCongreso no parece corroborada por el ejercicio de las atribuciones parlamentarias por parte de la oposición, ya que este tendría que mostrar de alguna forma clara y persistente

15 Cheibub (2007) pp. 136 y siguientes.

16 La doctrina nacional, con distintos matices, incluye nuestro régimen presidencial dentro de los vigorizados, reforzados o neopresidencialismos. Se utiliza el término neopresidencialismo para referirse a un presidencialismo vigorizado cuyas facultades los "convierten en verdaderas dictaduras", que es la crítica que sostuvo en su oportunidad el Grupo de los 24; Geisse y RAMírez (1989) p. 29. Garretón señala que la Constitución consagra dentro de sus instituciones la "preeminencia absoluta del poder presidencial"; Garretón (1990) p. 182. Según José Luis Cea "existe un evidente desequilibrio de potestades a favor del Presidente de la República con respecto al Congreso Nacional y a los demás órganos estatales aludidos”. En una versión previa de su tratado (1998) los términos son más enfáticos; CEA (2002) pp. 117, 97 y 98. Oscar Godoy señalaba que es evidente que el "régimen ultrapresidencialista" creado por la Constitución de 1980 "establece una hegemonía abrumadora del Poder Ejecutivo sobre el Legislativo”; Godoy (1990) p. 26 y Godoy (2003) p. 12.

17 Uno de estos índices es el que elabora el semanario The Economist. En él se evalúan más de ciento cincuenta regímenes democráticos en ocho tópicos, uno de los cuales es el funcionamiento del gobierno. Este último tópico incluye quince ítems que, entre otros temas, miden la participación de representantes libremente elegidos en la creación de políticas públicas; el poder y primacía del Congreso como órgano político; el sistema de frenos y contrapesos en relación con el poder del Gobierno; la libertad de las instituciones democráticas ante la influencia de las fuerzas armadas, potencias extranjeras, entidades económicas, religiosas u otras organizaciones; la responsabilidad del gobierno entre elecciones; la transparencia y apertura del gobierno; la extensión de la corrupción; la capacidad de la administración pública de implementar con éxito políticas de gobierno; la confianza en el gobierno y en los partidos políticos, etc. En los años 2008, 2010, 2012 y 2014, entre los presidencialismos, Chile ocupa el cuarto lugar en la evaluación global de las democracias del mundo (después de Uruguay, Estados Unidos y Costa Rica) y en el tópico funcionamiento de gobierno es el mejor evaluado, salvo el año 2012 en que sigue de cerca a Uruguay. Disponible en <graphics.eiu.com/PDF/Democracy_Index_20**_web.pdf>. 
el rechazo a las prerrogativas o privilegios parlamentarios que identifican al mencionado presidencialismo reforzado. Es más, dado el predominio de períodos de gobierno dividido después de marzo de 1990, una respuesta política predecible ante el uso y abuso de los privilegios constitucionales del Presidente de la República tendría que haber sido el bloqueo o ralentización del trámite parlamentario del programa legislativo presidencial, lo que no ha ocurrido $^{18}$.

Otra posibilidad es que las atribuciones presidenciales que conforman el reforzamiento del presidencialismo erigido por la Constitución vigente, tengan en su aplicación práctica un efecto de menor envergadura en el equilibrio de poderes, tanto por factores políticos como por factores de orden jurídico. La incidencia menor de las facultades presidenciales exorbitantes fundamenta aquella doctrina que sostiene que la relación entre Presidente y Congreso no está dominada por la primacía del primero sino por la cooperación o colaboración entre ambos poderes políticos ${ }^{19}$. Esta colaboración explicaría de mejor manera la influencia del Congreso Nacional en el sistema político chileno y, en particular, la participación significativa de ambas cámaras en decisiones relevantes para la conducción y gestión del gobierno. Dicha colaboración es la que permitiría que los intereses políticos de los diputados y senadores tengan incidencia y, eventualmente, formen parte de las decisiones presidenciales (normativas y no normativas) que se encuentran sometidas a la potestad constitucional del Congreso Nacional. A su vez, la presencia de los intereses políticos de los parlamentarios en los procesos decisorios tiene un efecto favorable sobre el sistema democrático pues contribuye a la adaptación y orientación de las políticas de gobierno al interés público $^{20}$.

Ahora bien, para sostener que existe una cierto grado de colaboración entre las Cámaras legislativas y el Presidente de la República es menester identificar la influencia aceptada o consentida que ejercen estas (y sus integrantes) en las decisiones del Poder Ejecutivo. En tanto esta influencia exista y tenga una incidencia relevante para el resultado o decisión presidencial, es posible afirmar que opera una relación de cooperación o colaboración. Si dicha influencia no existe o carece de incidencia en la decisión presidencial, no hay relación de cooperación, sino mera primacía y tal primacía es difícil de compatibilizar con un régimen democrático estable y sustentable en el tiempo ${ }^{21}$.

18 La expresión gobierno dividido alude a la existencia de una mayoría adversa al Presidente en una o ambas cámaras. Distinguimos esta situación de la ausencia de apoyo para lograr cambios constitucionales, que algunos autores denominan bloqueo. GARRETÓN (2001) pp. 192-195

19 Cox y Morgenstern (2002) p. 447; Siavelis (2002) p. 102; Angell (2003) p. 101; Nolte (2003) p. 64; Berríos y Gamboa (2006) pp. 101 y 109; Stein et al. (2006) p. 46 y 58; Boeninger (2008) pp. 200-201; Toro y García (2008) p. 408; y Aninat (2009) p. 129. En la historia reciente, Gil (1966) pp. 117-118; y AgOR (1971) p. xli.

20 Sostiene la doctrina que si no hay deliberación legislativa o esta es débil, pueden adoptarse políticas mal concebidas en lo técnico, poco ajustadas a las verdaderas necesidades o exigencias de los intereses organizados y de la ciudadanía, y carentes de consenso y, por lo mismo, insostenibles en el tiempo o de ejecución ineficiente o injusta. STEIN et al. (2006) pp. 44 y 37.

21 Esta es la valoración de las Asambleas iberoamericanas como rubber stamp legislatures, que solo aportan legitimidad democrática sin influencia sustantiva que encontramos en autores como ShUGART, CAREY y MAINWARING. 
Por lo dicho, el grado de influencia efectivo ejercido por los parlamentarios en el proceso de gobierno cubierto por sus competencias constitucionales es determinante para entender el funcionamiento de la democracia en su dimensión institucional. Lo anterior ubica en el centro de la reflexión sobre las relaciones Poder Ejecutivo-Poder Legislativo la participación efectiva del segundo en las decisiones del primero.

Aunque se ha intentado con mayor o menor éxito, parece claro que con rigor científico es difícil medir la influencia parlamentaria en la actividad de gobierno, incluso cuando se utilizan procesos con detallada expresión material como el legislativo ${ }^{22}$. Se suma a las dificultades inherentes a esta medición el carácter dinámico de la relación Presidente-Congreso en su faz política y partidista, pues ella cambia junto con los liderazgos personales y circunstancias políticas dominantes ${ }^{23}$.

La influencia parlamentaria sobre el Presidente de la República en el caso del presidencialismo chileno, al margen de las dificultades indicadas, tiene un componente que sí parece susceptible de ser explorado desde un punto de vista jurídico. Esto por cuanto antes de estudiar cómo se concreta y manifiesta la colaboración entre los poderes Legislativo y Ejecutivo, es necesario indagar de qué modo el Congreso Nacional enfrenta las atribuciones constitucionales que otorgan primacía al poder presidencial. No parece posible sostener que el Presidente de la República prescinde por simple decisión voluntaria de las atribuciones que configuran el presidencialismo reforzado. Es más plausible afirmar que existen factores políticos y jurídicos que relativizan el poderío de tales facultades.

El estudio de dichos factores es al menos posible respecto de una función, la legislativa, en uno de sus aspectos, el que corresponde a la selección de proyectos de ley que recibirán debate, estudio y votación en las cámaras parlamentarias. Esta posibilidad resulta de especial interés ya que el Presidente de la República tiene que transformar su programa electoral en las leyes que sirven para su implementación y, por lo mismo, debe promover la aprobación por ambas Cámaras de las iniciativas de su interés, lo que ubica en el centro del sistema político la función comentada ${ }^{24}$. En las secciones que siguen intentaremos explicar de qué modo el ordenamiento jurídico y las convenciones y prácticas parlamentarias han relativizado las atribuciones presidenciales extraordinarias para permitir su operación dentro de un conjunto de canales o vías que incentivan y fuerzan la colaboración entre Presidente y parlamentarios. Como explicaremos más abajo, la relación entre Poder Ejecu-

\footnotetext{
22 Una medida empleada ha sido la comparación de iniciativas legislativas presidenciales aprobadas en relación con las mociones parlamentarias aprobadas. Es claro que, en lo cualitativo, esta medición es insuficiente. Este índice básico se ha enriquecido con la medición del número de indicaciones, su naturaleza (formal, técnica, sustantiva nuclear o marginal, etc.), su origen (gobierno u oposición) y resultado (rechazada, aprobada en parte o totalmente), sin embargo sigue dejando en una zona oscura algo tan importante como el contenido y relevancia política de la influencia ejercida. Lo cualitativo puede añadirse con la opinión o encuesta de élites o cobertura de medios de comunicación social, pero el aumentar las variables en observación la posibilidad de revisar un período legislativo extenso disminuye. Russell y Benton (2009) pp. 6-11. Berríos y Gamboa (2006) pp. 110112 enfrentan el problema con argumentos cualitativos sobre base cuantitativa.

23 Altman (2008) p. 64.

24 Que en buen parte coincide con la capacidad legislativa del Congreso y los parlamentarios identificada por Aninat como uno de los tres elementos que fijan el balance de poderes entre Presidente y Congreso. ANINAT (2009) p. 48.
} 
tivo y Poder Legislativo en el ejercicio de la función legislativa exhibe una organización que dispone de mecanismos colaborativos que se alejan del modelo de predominio presidencial identificado por nuestra doctrina.

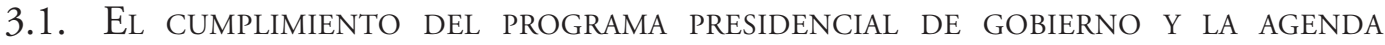 LEGISLATIVA \\ El cumplimiento del programa de gobierno que cimentó la elección popular del} Presidente de la República depende en buena parte de su potestad legislativa, ya que la ley es el vehículo de decisión e implementación de las políticas públicas de mayor envergadura económica, política y social ${ }^{25}$. Lo anterior otorga a la regulación del proceso legislativo un carácter esencial para el funcionamiento adecuado del sistema democrático.

El proceso legislativo contiene mecanismos que permiten seleccionar las mociones y mensajes que recibirán tramitación efectiva y que, por lo mismo, tienen una mayor probabilidad de generar el consenso que las convertirá en ley. La tramitación efectiva de un proyecto comienza con su ingreso, formal y material, a la denominada agenda legislativa que solo incluye a las iniciativas que recibirán estudio y debate en Sala y comisión, y que excluye a aquellas mociones y mensajes que, una vez presentados en la Oficina de Partes de la cámara de origen, no avanzan -ni avanzarán- de modo relevante en su trámite legislativo.

El poder de agenda es el poder de incluir o excluir proyectos de ley en la agenda legislativa, como también la facultad de decidir el tipo de procedimiento de debate y votación que recibirán ${ }^{26}$. La selección de los proyectos de ley que ingresarán a la agenda legislativa es un componente central del poder de agenda (o agenda setting) descrito por Tsebelis $^{27}$. Tanto para el Presidente como para diputados y senadores, la influencia y control sobre la agenda legislativa constituyen un componente esencial de su posición en el sistema político. Cox y McCubbins sostienen que el principal poder de los grupos parlamentarios o bancadas es, precisamente, el de agenda, incluso por sobre el poder de control que se tiene sobre el voto de los parlamentarios ${ }^{28}$. Autores como Schattschneider van más allá y sostienen que el poder de agenda es el poder político ${ }^{29}$.

La construcción de la agenda legislativa depende de dos componentes, uno positivo y otro negativo. El componente positivo es la facultad de incluir un determinado proyecto de ley en el orden de los asuntos por tratar en la Sala o en comisión y, luego, determinar el procedimiento adecuado para lograr su efectiva tramitación hasta su votación final por la Sala. El componente negativo es la potestad de excluir o postergar el debate o votación de

\footnotetext{
25 Explican este fenómeno, en parte, factores jurídicos (como las restricciones constitucionales que exigen la intervención legislativa en la regulación de determinadas materias), políticos (la necesidad de generar apoyo político mediante el debate y votación en una asamblea representativa y democrática) y sociales (por el lugar que ocupa la ley en la configuración de los deberes sociales). BronfmAn (2012) pp. 75 y 76.

26 Puede también entenderse, de modo más simple, como el poder de asegurar o prevenir que un proyecto de ley sea debatido y votado en una cámara parlamentaria.

27 Tsebelis (2002) pp. 2-6.

28 Cox y McCubbins (2005) pp. 20-25. La tesis de estos autores, referida al Congreso Federal norteamericano, es que este poder de agenda se encuentra cartelizado

29 La determinación de alternativas es el supremo instrumento de poder. SCHATTSCHNEIdER (1960) p. 68.
} 
un proyecto de ley en Sala o comisión, o bien de ralentizar la tramitación de un proyecto de ley que ha recibido algún debate o votación no conclusiva de la competencia camaral. Ambos componentes no pueden disociarse pues el éxito en la tramitación de un proyecto de ley ingresado a trámite no solo depende de la voluntad política de debatirlo y aprobarlo, sino también de la voluntad política de no obstaculizar o dificultar su tramitación. Lo segundo es tan relevante que algunos autores sostienen que el verdadero poder de los partidos políticos en el parlamento es su capacidad de establecer aquello que no se debatirá ni votará $^{30}$. En la práctica parlamentaria norteamericana la importancia de una de las manifestaciones de este poder es tal que merece un nombre propio, el filibusterismo ${ }^{31}$.

En principio, comparten el poder de agenda positivo y negativo el Presidente de la República y la mayoría parlamentaria, como también el presidente de la correspondiente cámara o comisión legislativa y, hasta cierto punto, los parlamentarios individualmente considerados. Sin embargo, existen diferencias importantes en la distribución del poder de agenda positivo y negativo. El poder positivo de adoptar decisiones sobre la inclusión de un proyecto en la agenda legislativa no se distribuye de modo homogéneo entre sus titulares formales. Así, en su componente positivo tiende a beneficiar solo al Presidente y los líderes parlamentarios, que pueden ser presidentes de la cámara o comisión, integrantes de la Mesa, jefes de bancada o comité, u a otros cargos extraparlamentarios (v. gr. presidente de un partido político).

Por otro lado, el poder de agenda negativo, que también pertenece al Presidente y los parlamentarios en lo formal, tiende a distribuirse de modo más disperso (y a veces uniforme) entre los parlamentarios individuales, quienes pueden obstruir el trámite de un proyecto mediante las facultades que les otorga el ordenamiento jurídico intracamaral. El poder de agenda negativo puede convertirse en obstruccionismo en aquellos casos en que la exclusión o retardo afecta un proyecto promovido en ejercicio del poder de agenda positivo. La delgada línea que separa el poder de agenda negativo del obstruccionismo se traza con la legitimidad o aceptación de los parlamentarios de la cámara respectiva de la acción concreta dirigida a excluir o retardar. Si ella ha sido aceptada por la amplia mayoría de los parlamentarios o bien forma parte de una práctica o convención reconocida en el tiempo, puede utilizarse la expresión poder de agenda negativo. Si, por el contrario, la acción dirigida a excluir o retardar no es aceptada por la mayoría de los congresistas ni tampoco es práctica o convención reconocida y tiene un carácter coyuntural, puede recibir la calificación de obstruccionismo. El obstruccionismo puede enfrentarse concentrando el poder resolutivo sobre lo procedimental en los órganos de gobierno colectivo (presidente o Mesa) y en los líderes de los grupos parlamentarios o partidos. Esta concentración, por cierto, menoscaba la efectividad de la representación democrática que cada parlamentario ostenta.

Como es lógico, en un régimen democrático, la facultad de incluir proyectos de ley en la agenda legislativa no depende de modo exclusivo del Presidente como tampoco de

\footnotetext{
30 Cox y McCubbins (2005) pp. 5, 34, 37, 38.

31 Suele referirse al procedimiento parlamentario dirigido a extender de modo innecesario el debate con el objeto de retrasar o evitar el voto de una propuesta determinada. Incrementa la visibilidad de la oposición a un proyecto de ley.
} 
los integrantes de una u otra rama del Congreso, aun cuando la atribución constitucional se radique institucionalmente en dichas magistraturas. Lo cierto es que un conjunto de factores sociales, políticos, económicos y jurídicos impulsan a los agentes políticos a priorizar el debate de determinados proyectos y a postergar, preterir o excluir a otras iniciativas legislativas ${ }^{32}$. En tal sentido, la construcción de la agenda legislativa está de modo intenso condicionada por variables políticas que escapan al ámbito resolutivo de los representantes populares ${ }^{33}$.

\subsection{Dos ElEMENTOS DETERMinANTES DE LA CONFORMACiÓN DE LA AGENDA LEGISLATIVA} EN CHILE

Como en otros regímenes constitucionales, el proceso legislativo chileno está condicionado por dos decisiones ajenas a la disciplina jurídica y que pertenecen por completo al ámbito de la política: un marco temporal que, mediante la programación de sesiones y su duración, acota o limita la posibilidad de estudio y debate de las iniciativas de ley y una manifiesta tendencia a la primacía cuantitativa de los mensajes sobre las mociones como origen de la ley.

En Chile, se publican por año cerca de setenta leyes, que se aprueban en el contexto de un ingreso anual de aproximadamente trescientas iniciativas legislativas en la Cámara y poco menos de doscientas en el Senado ${ }^{34}$. Luego, en promedio, menos de una quinta parte de todas las iniciativas legislativas culminan su trámite parlamentario como leyes. Esta situación no difiere de la realidad de otras Asambleas y la forma de enfrentar este inevitable proceso de selección nace tanto de la regulación del proceso legislativo como de las convenciones parlamentarias y políticas asentadas y aceptadas por los integrantes del Congreso Nacional.

Para explicar este resultado, como se indicó antes, puede comprobarse que el tiempo destinado a trabajo legislativo es limitado. La capacidad de las dos cámaras de estudiar, debatir y aprobar proyectos de ley está acotada por el tiempo destinado a sesiones, el que, a su vez, es un componente del conjunto de tareas asumidas por los congresistas. El año 2013,

32 Factores de distinta índole incrementan o disminuyen la posibilidad de ingresar a la agenda legislativa de determinados proyectos de ley: sociales, como el efecto positivo o negativo de una propuesta normativa sobre un porción significativa de la sociedad; políticos, como la necesidad de exhibir una norma como resultado alcanzado antes de una elección o como respuesta a una catástrofe natural; jurídicos, como la derogación de una norma importante del ordenamiento jurídico como consecuencia del control de constitucionalidad. Eizenstat, un asesor del Presidente norteamericano en el período 1977-1981, señala como factores que inciden en la construcción de la agenda política presidencial, los compromisos de campaña, el comportamiento de los mercados financieros, la actividad de la prensa, los intereses del gabinete y de los congresales; EIZENSTAT (1990) pp. 4-17.

33 En la comunidad política democrática coexisten, al menos, una agenda de los medios de comunicación masiva, una agenda pública, una agenda política y una agenda legislativa. Walker sostiene que la agenda legislativa positiva puede entenderse como una línea continua que va desde aquello que debe debatirse y votarse (por razones jurídicas o necesidad política) a aquello que solo se debatirá y votará si es promovido por uno o más congresistas. WALKER (1977) pp. 424 y 425.

34 El Boletín Estadístico de la Cámara de Diputados señala que el año 2013 ingresaron a la Cámara de Diputados 294 proyectos del ley, iniciativas que se dividen en 212 mociones y 82 mensajes; Oficina de Informaciones de la Cámara de Diputados de Chile (2013) p. 1. En el Senado se admitieron a trámite 153 mociones de senadores y 23 mensajes del Presidente; Departamento de informaciones del Senado (2014) pp. 7 y 10. 
por ejemplo, la Cámara de Diputados celebró ciento tres sesiones ordinarias (de ordinario, tres por semana, de tres horas de duración) a las que deben sumarse sesiones de comisión (que pueden llegar a dos por semana) ${ }^{35}$. En el Senado, en el mismo período, se celebraron sesenta sesiones ordinarias, también de cerca de tres horas cada una ${ }^{36}$. En un ejercicio simple, si se toman las cerca de quinientas iniciativas y se dividen por el número total de sesiones de sala de la Cámara y el Senado, el resultado es que en cada sesión se debiesen debatir y votar cerca de tres proyectos de ley, sin distinguir entre sesiones destinadas a aprobación en general y aprobación en particular y sin considerar el trámite en comisiones, ni el ejercicio por la Sala o comisión de otras competencias constitucionales. Dicho resultado revela que, a menos que se aumente significativamente el número de sesiones de Sala y comisión (en probable desmedro de otras funciones parlamentarias), no es viable dar trámite a todos los proyectos ingresados al proceso legislativo.

Por otro lado, a juzgar por los resultados del proceso legislativo, es el Presidente de la República quien exhibe mayor influencia en la construcción de dicha agenda. Así, en el período 1990-2010, si bien el 75\% de los proyectos de ley ingresados a trámite parlamentario corresponden a mociones y el $25 \%$ a mensajes, en el total de leyes publicado en el mismo período, es posible comprobar que el $75 \%$ corresponde a leyes que han tenido su origen en mensajes y solo el $25 \%$ a leyes originadas en mociones ${ }^{37}$. En armonía con lo planteado antes, los números del período no solo revelan la primacía presidencial, sino también que un número importante de mociones parlamentarias no reciben debate ni pronunciamiento de las cámaras o sus comisiones.

\subsection{TRES Dimensiones RELEVANTES EN LA REgUlaCión DE LA AGENDA LEGISLATiVA EN CHILE}

La conformación de la agenda legislativa responde a una voluntad política que se manifiesta, de acuerdo con normas jurídicas, en tres dimensiones determinantes para el éxito de la iniciativa legislativa, a saber, materia, plazos y procedimiento ${ }^{38}$. Esto es, el debate, votación y aprobación de un proyecto de ley podrá efectuarse en tanto se cuente con la voluntad y el consenso político requerido y se respeten las normas que regulan su tramitación en las tres dimensiones indicadas.

La regulación aplicable a cada una de estas dimensiones condiciona las decisiones de los agentes políticos de modo significativo, ya que dependiendo de las facultades otorgadas por la norma, se erige para cada agente del proceso decisorio una posición negociadora más

\footnotetext{
35 Recordemos que, tanto la Cámara como el Senado reservan una semana al mes para el trabajo parlamentario en el correspondiente territorio electoral, que se resta al tiempo de trabajo legislativo. Destacamos que las comisiones permanentes de la Cámara de Diputados que tuvieron más sesiones, la de Constitución con 78 sesiones y la de Hacienda con 71 sesiones, evacuaron 16 y 33 informes respectivamente.

36 Sus comisiones con más sesiones, la de Constitución, Legislación, Justicia y Reglamento con 75 y la de Hacienda con 49, elaboraron 32 y 50 informes respectivamente.

37 Elaborado con datos obtenidos por el autor. Olson observa una tendencia general: sostiene que el $90 \%$ de la agenda legislativa tiene su origen en el gobierno y que al menos el $90 \%$ de lo propuesto por el Gobierno es aprobado. OLSON (1994) p. 84.

38 Procedimiento entendido, por cierto, sin el componente materia y plazo.
} 
o menos fuerte. Dicha posición negociadora configura la extensión del poder de agenda de los parlamentarios.

El primer elemento determinante para el acceso de un proyecto de ley a trámite legislativo y luego para el progreso en su tramitación, es la materia de la iniciativa legal. La materia tiene directa incidencia en el titular de la potestad que permite dar inicio al trámite legislativo. Si se trata de un proyecto de ley recaído en una materia que forma parte del listado de asuntos propios de iniciativa exclusiva del Presidente, solo dicha magistratura puede suscribir y presentar el proyecto a trámite en la oficina de partes competente. Si la materia no pertenece al ámbito reservado de modo exclusivo al Presidente de la República, el proyecto de ley correspondiente puede ser presentado a tramitación por cualquier parlamentario cumpliendo con las exigencias de la Carta Fundamental.

El segundo elemento determinante para el debate, votación y aprobación de un mensaje o moción es la existencia o inexistencia de un plazo para la tramitación del proyecto de ley. Este plazo puede provenir de normas constitucionales o legales, como también de acuerdos o normas internas del parlamento. En la regulación del procedimiento legislativo chileno existe la facultad presidencial de imponer un plazo máximo para el pronunciamiento de cada Cámara -en cada trámite- sobre un determinado proyecto de ley mediante la declaración de urgencia ${ }^{39}$. También existe un plazo constitucional de dos meses para el despacho del proyecto de Ley de Presupuestos, cuyo incumplimiento conduce a la aprobación tácita del proyecto presidencial. Fuera de los supuestos constitucionales, los plazos de tramitación de los proyectos de ley provienen de la decisión del propio órgano parlamentario.

El tercer elemento determinante para el debate, votación y aprobación de un mensaje o moción es la regulación del procedimiento disponible para su trámite en cada Cámara legislativa. La discusión y aprobación de un proyecto de ley puede someterse a distintos procedimientos previstos por la regulación interna ${ }^{40}$. La configuración de cada uno de estos procedimientos incide de modo directo en el tiempo destinado al debate, votación y aprobación de la iniciativa y, por lo mismo, en la velocidad del trámite y la viabilidad de lograr la conversión del proyecto en ley.

En la práctica, la suma de normas jurídicas y convenciones parlamentarias sobre materia, plazo y procedimiento generan un conjunto de poderes de agenda positivos y negativos disponibles para los diversos agentes políticos que intervienen en la formación de la ley. Las tres dimensiones anotadas son interdependientes, lo que las convierte en objeto de una discusión y negociación política, por lo común, integrada o fusionada. Tanto es así que es probable que el uso no consensuado de una prerrogativa en una de las dimensiones (por ejemplo, la declaración de discusión inmediata por parte del Presidente en la dimensión plazo) afecte de modo negativo el progreso de la iniciativa en la dimensión procedimiento.

\footnotetext{
39 Art. 74 Constitución Política (en adelante CPR). Esta facultad exige el despacho de un proyecto en el plazo de treinta días, doce o seis días (arts. 27 y 28 de la LeY No 18.918 DE 2010, Orgánica Constitucional del Congreso Nacional, en adelante LOCCN).

40 Pueden también crearse procedimientos ad hoc, como el utilizado en la tramitación de los proyectos denominados "ley corta". La facultad de suspender la aplicación de los reglamentos camarales permite, de hecho, establecer reglas de trámite particulares.
} 
Los hechos parecen demostrar que la construcción de la agenda legislativa es consensuada con el apoyo de un número de diputados y senadores muy superior a la mayoría simple. El poder de agenda de los congresistas -y especial el extendido poder de agenda negativo- explican la modalidad consensual con que el Presidente utiliza sus poderes de agenda positivos ${ }^{41}$. Dicha modalidad es básica para lograr la aprobación de cerca de setenta proyectos de ley cada año, dato independiente de las mayorías dominantes en ambas cámaras.

En las secciones que siguen revisaremos cada una de las dimensiones decisivas para el funcionamiento de la agenda legislativa, con el propósito de identificar y cualificar las posiciones que el ordenamiento jurídico otorga en cada una al Presidente de la República y congresistas.

\subsubsection{En poder de agenda en relación con la materia objeto de regulación legal}

La materia que será objeto de regulación por medio normas jurídicas generales y permanentes con rango de ley condiciona las decisiones iniciales de los agentes políticos dirigidas a su inclusión en la agenda legislativa. Supuesta la conveniencia o necesidad política o social de elaborar una determinada regulación legal, el contenido o materia del proyecto incidirá de modo significativo en la decisión del Presidente o congresistas de iniciar o no iniciar el trámite pertinente. De modo preliminar, es posible afirmar que el Presidente de la República disfruta de una posición jurídica de privilegio en relación con la materia por su control sobre el extenso listado de contenidos que conforman la iniciativa exclusiva, cuestión que se explicará abajo.

En principio, el ordenamiento constitucional puede configurarse, en lo que respecta a las materias objeto de regulación, de dos modos distintos y opuestos: con reserva de materias propias de ley (dominio máximo legal en la terminología usual) o sin reserva de materias propias de ley. Si existe dominio máximo legal, el campo de la potestad legislativa de los parlamentarios se ve reducido, lo que merma su poder de agenda en faz positiva. La reducción derivada del dominio máximo legal beneficia al Presidente por el ensanchamiento de su potestad reglamentaria en todas aquellas materias que no son propias de la ley. Este beneficio redunda en un cierto incremento de su potestad de agenda positivo, que aunque no dice relación directa con la ley, le entrega opciones de actuación normativas no sometidas al debate y aprobación parlamentarios.

A la inversa, si el dominio legal carece de fronteras en cuanto a materias, el poder de agenda positivo de los parlamentarios es más fuerte ${ }^{42}$. En uso de sus facultades constitucionales los congresistas pueden promover proyectos de ley en cualquier área de su interés político, económico, social o cultural. En términos comparados, el Presidente pierde, pues

\footnotetext{
41 También es relevante el poder de agenda positivo de los congresistas. En su ejercicio incidirá el marco temporal fijado por el mandato presidencial y el mandato parlamentario (y la posibilidad de reelección), como también la importancia política, social y económica de la propuesta regulatoria. A estos factores debe añadirse, su relevancia en la agenda partidista o personal, y el poder o influencia del o de los patrocinantes sobre el Poder Ejecutivo y sobre su propia bancada.

42 Sin perjuicio de otras restricciones provenientes de la propia Carta Fundamental que derivan, por ejemplo, de exigencias de tutela de derechos fundamentales y que fuerzan que la intervención estatal mediante ley y no otro instrumento.
} 
debe compartir su poder de agenda positivo con parlamentarios que pueden iniciar proyectos en todo aquello que estimen pertinente, incluso invadiendo campos que el Poder Ejecutivo considera como propios ${ }^{43}$.

Un segundo aspecto relevante para la cuestión analizada es la creación por el ordenamiento constitucional de una reserva de iniciativa sobre contenidos determinados en beneficio del Presidente de la República o de los congresales. Su reconocimiento constitucional, en directa relación con la existencia o inexistencia de un dominio máximo legal, tiene gran relevancia en el poder de agenda positivo del beneficiado, en especial por el efecto de exclusión de los restantes sujetos dotados de iniciativa.

Como puede suponerse, la existencia de iniciativa exclusiva, genera un importante desequilibrio en el poder de agenda positivo. Tiene, además, un impacto relevante en el poder de agenda negativo, ya que las restricciones o barreras impuestas al poder de agenda en su faz positiva condiciona el ejercicio del poder de agenda en su faz negativa. En un régimen constitucional dotado de iniciativa exclusiva presidencial extensa, el rechazo sistemático de iniciativas presidenciales o la postergación de su debate podrían privar al Congreso de proyectos de ley relevantes para debatir e inducir un bloqueo institucional en el cual el Presidente no tenga otra alternativa que recurrir a otras opciones normativas o ejecutar su programa de gobierno sin contar con normas ${ }^{44}$. En este orden de cosas, conviene al Congreso reconocer al Presidente una posición robusta en el acceso a la agenda legislativa, como también un cierto poder en la priorización de los proyectos de ley que recibirán tramitación parlamentaria, como vía para atraer al foro parlamentario asuntos legislativos de relevancia política. Del mismo modo, conviene al Presidente abrir una vía de acceso a parte de su poder de agenda positivo, para permitir a los congresistas incorporar su propia agenda legislativa en faz positiva a cambio del reconocimiento parlamentario del poder presidencial de priorizar algunos proyectos de ley ${ }^{45}$.

\footnotetext{
43 Este punto fue debatido en el régimen constitucional de 1925. La Carta de 1925 enumeraba, de modo no taxativo, quince materias de ley en su artículo 44. Dicho listado, en opinión de la doctrina, llamaba al legislador a intervenir en problemas "particulares, transitorios, secundarios", atentando contra la generalidad de la ley; Silva Bascuñán (1963) p. 148. Cumplido sostiene que en el período 1939-1958, 5136 leyes de un total de 6921 son formalmente leyes, "pero en sustancia son actos de administración"; Cumplido (1970) p. 179. Lo cierto es que la fórmula constitucional de 1925 invitaba a pensar que la ley podía extenderse "a todos aquellos asuntos que no están entregados a otras autoridades por la propia Constitución, y siempre que no contravengan lo preceptuado por esta”; Bulnes (1967) p. 62. Desde los ańos cuarenta del siglo pasado, el Presidente de la República defendió que le correspondía la administración financiera y económica de la Nación y, por ende, la responsabilidad exclusiva de su manejo, lo que llevaba a concluir "que los parlamentarios no tengan derecho alguno de iniciativa en esta materia”; Mensaje de la reforma constitucional presentada en julio de 1964 por el presidente Jorge Alessandri cit. por Silva Bascuñán (1970) p. 92. En parte, las ideas críticas ante la ilimitada iniciativa legislativa parlamentaria fueron recogidas, sin acotar el campo de la ley, mediante las reformas constitucionales que incrementan la iniciativa exclusiva presidencial en 1943 y 1970.

44 Es claro que el abuso del poder de agenda negativo puede incentivar el uso de la potestad reglamentaria. En los hechos, en Iberoamérica, la facultad reglamentaria ha representado una importante fuente de ampliación de los poderes del presidente, en desmedro del poder normativo del Congreso; Valencia (1979) p. 111.

45 Transacciones políticas de este tipo se observaron durante la vigencia de la Carta de 1925; Tapia (1960) p. 43. LA LEY No 20642 de 11 de diciembre de 2012 sugiere la pervivencia de esta práctica: junto con otorgar un reajuste de remuneraciones, aguinaldos y otros beneficios a los trabajadores del sector público, modifica la planta de oficiales de la Policía de Investigaciones y regula la pesquería del bacalao (artículos 33 y 34 ).
} 
De acuerdo a lo dicho, el poder de agenda del Presidente varía según la pertenencia de la materia al ámbito de la ley y la existencia o inexistencia de un campo de reserva de iniciativa en su beneficio.

En Chile el poder de agenda positivo del Presidente de la República, en relación con la materia, es robusto como consecuencia de la existencia de un dominio máximo legal y de una extensa iniciativa exclusiva. La iniciativa exclusiva reservada al Presidente por el artículo 65 CPR le permite decidir sobre la inclusión o exclusión de las materias allí listadas en la agenda legislativa ${ }^{46}$. Los parlamentarios carecen de herramientas jurídicas para cuestionar la ausencia de proyectos en una determinada materia y, ante la presentación de un mensaje, solo cabe dar inicio a su tramitación conforme con los procedimientos, convenciones y prácticas parlamentarias vigentes. La reserva de iniciativa legislativa en favor del Presidente incrementa su poder de agenda positivo y disminuye, proporcionalmente, el poder de agenda negativo de quienes carecen de iniciativa.

Prima facie podría pensarse que el poder que deriva del artículo 65 CPR resulta reforzado por la potestad reglamentaria autónoma (art. $32 \mathrm{~N}^{\circ} 6 \mathrm{CPR}$ ) y por la facultad del Presidente de solicitar la delegación de facultades legislativas (art. 64 CPR). Sin embargo, en la práctica, el ámbito de la potestad reglamentaria autónoma se ha delimitado de un modo más bien restrictivo y el uso de la delegación de potestad legislativa se ha concentrado en asuntos normativos propios de la organización interna del Poder Ejecutivo ${ }^{47}$.

Por otro lado, los congresistas chilenos, en claro contraste con las prerrogativas presidenciales, disfrutan de un poder limitado de agenda en su faz positiva. El dominio máximo legal del artículo 63 CPR y la comprensiva enumeración de materias incluida en la iniciativa exclusiva del Presidente, acotan de modo sensible la posibilidad de diputados y senadores de iniciar proyectos de ley. También contribuye a esta limitación, aunque en menor medida, el origen reservado, que impide a diputados y senadores iniciar proyectos de ley sobre materias que, según el artículo $65 \mathrm{CPR}$, deben tener su origen en la otra Cámara. A esta restrictiva configuración del ámbito de la iniciativa parlamentaria, deben sumarse factores políticos y organizativos que desincentivan su ejercicio.

El conjunto de reglas expuestas sugiere, que al menos en lo que atañe al ordenamiento constitucional y legal, el balance en Chile del poder de agenda positivo asociado al acceso de un proyecto de ley a trámite legislativo, en lo referido a la materia, es favorable al Presidente y desfavorable para los congresistas. Este hecho no resulta alterado por las facultades parlamentarias de control de admisibilidad de proyectos de ley, las que sobre la base

\footnotetext{
46 La reserva formal de materias de gran relevancia política, económica y social mediante la iniciativa exclusiva, dificulta reconocer que, de todos modos, la intervención legislativa en asuntos de interés general suela ser promovida por quien disfruta de los recursos técnicos y políticos para diseñarla e implementarla. Esto explica que aún en paises sin reserva de iniciativa, los proyectos de ley de mayor envergadura política sean impulsados desde el Poder Ejecutivo.

47 Ribera (2001) pp. 486-487, Cordero (2009) pp. 415, 427 y 433, Cordero (2010) p. 152. Entre el $1^{\circ}$ de enero de 1990 y el 31 de diciembre de 2014 se aprobaron y publicaron 1.116 Decretos con Fuerza de Ley. De ellos solo 38 fijan textos refundidos (3\%). De los restantes 1078, el contenido predominante es la reorganización de la Administración Pública, reforma de planta y escalafones. NúNEzZ (2015) pp. 5, 37 y 43.
} 
de una interpretación estricta podrían generar cierto poder de agenda en su faz negativa ${ }^{48}$. Aunque la inadmisibilidad se declara con cierta frecuencia, no es un instrumento que se utilice de modo regular para ejercer un poder de agenda negativo, probablemente porque se trata de una resolución que debe contar con un fundamento jurídico ${ }^{49}$. Tampoco suele utilizarse para ejercer un poder de agenda positivo, entre otras razones, porque la decisión adoptada en las Cámaras podría ser revisada en su constitucionalidad por el Tribunal Constitucional (artículo 93 No 3 CPR). De todos modos, notemos que la inadmisibilidad de un mensaje, moción, observación o indicación, fundada en el voto de una mayoría simple de una cámara, sustrae del debate los contenidos normativos sobre los que recae, lo que la convierte en una herramienta política y jurídica que podría servir para incidir sobre la conformación de la agenda legislativa.

Dada la extensión del poder presidencial en el tópico que comentamos, diputados y senadores han creado procedimientos y prácticas para promover la inclusión de iniciativas sobre materias de su interés en la agenda legislativa en aquellos casos en que estas pertenecen al ámbito de la iniciativa presidencial. Estas herramientas, extraconstitucionales, pueden ser formales o informales. Dentro de las informales destaca la negociación directa con el Poder Ejecutivo (de ordinario con ministros de Estado) dirigida a obtener que el Presidente elabore y promueva una determinada propuesta legislativa ${ }^{50}$. Las herramientas formales son las peticiones parlamentarias, que a través de oficios y acuerdos, se dirigen al Presidente para que inicie o suscriba una propuesta legislativa de un diputado o senador cuyo contenido forma parte de la iniciativa exclusiva reservada al Jefe de Estado ${ }^{51}$. También puede considerarse como una alternativa formal disponible para el mismo propósito, la utilización de la reforma constitucional para promover un cambio en el ordenamiento jurídico

48 Por ejemplo, interpretando de manera restrictiva los contenidos de la iniciativa exclusiva en beneficio de mociones parlamentarias.

49 A diferencia de otro tipo de facultades de naturaleza política disponibles para los parlamentarios. Pero se ha utilizado: en la tramitación de la LEY No 20120, las observaciones del Presidente de la República fueron consideradas inadmisibles por el Presidente del Senado que las consideró ajenas a las ideas matrices del proyecto. También el Presidente de la Cámara de Diputados declaró inadmisibles, por la misma razón, once de las veintiocho observaciones presidenciales formuladas al proyecto de ley que introduce la televisión digital terrestre (tramitación de la LEY No 20.750).

50 Dicha negociación puede forzarse con decisiones como la de rebajar una partida de gastos variables del proyecto de ley de presupuestos a un valor simbólico (por ejemplo, un peso). También se ha asentado la práctica de negociar con las mayorías parlamentarias los contenidos de las observaciones presidenciales, antes de su envío a tramitación. Sото (2015) p. 207.

51 "Patrocine" en el lenguaje empleado por nuestros parlamentarios. En el año 2013, pueden contarse más de cuarenta Acuerdos aprobados por el Senado en que se solicita, directa o indirectamente, al Presidente de la República iniciar el trámite legislativo en una determinada materia perteneciente a su iniciativa exclusiva; DEPARtamento de informaciones del Senado (2014) pp. 40-80. En la Cámara de Diputados, se registran al menos treinta y nueve Acuerdos que solicitan o suponen el ejercicio de iniciativa legislativa presidencial, en un total de ciento diecinueve Acuerdos aprobados por la Corporación; Oficina de Informaciones de la CÁmara De DipuTADOS DE CHILE (2013) pp. 17-21. De ordinario se trata de peticiones generales, aunque existen Acuerdos que contienen el texto de una indicación o norma en particular. 
que afecte normas de rango legal en el ámbito de reserva del artículo $65 \mathrm{CPR}$, toda vez que no existe iniciativa exclusiva presidencial en el capítulo XV de la Carta Fundamental ${ }^{52}$.

\subsubsection{El poder de agenda en relación con el plazo de tramitación}

Una segunda dimensión relevante de la agenda legislativa es el plazo previsto para la tramitación de los proyectos de ley. El plazo puede tener su origen en una norma o precepto constitucional, legal o reglamentario, o bien derivar de una convención parlamentaria $^{53}$. La existencia de un plazo para el debate y votación de un proyecto de ley que inicia su tramitación fuerza el progreso de su trámite en el proceso de formación de la voluntad legislativa. En el caso de que exista un plazo su incidencia sobre la agenda legislativa tendrá una relación directa con los efectos derivados de su incumplimiento (aprobación tácita, preferencia, caducidad de la iniciativa u otro).

Ahora bien, si el trámite legislativo no se encuentra sometido a ningún plazo, el acceso de un proyecto de ley al orden del día de la Sala y la comisión (y su avance) dependerá solo de la suma de decisiones de los representantes populares adoptadas en ejercicio de su poder de agenda positivo y negativo. En el Congreso Nacional, en el período que va entre el 11 de marzo de 2006 y 10 de marzo de 2010 fueron debatidos, votados y publicados como ley, noventa y siete proyectos de ley que no gozaron de ningún tipo de urgencia, en contraste con doscientas cuarenta y dos iniciativas de ley, promulgadas y publicadas como tales, que recibieron una o más calificaciones de urgencia ${ }^{54}$.

Como se señaló antes, si el trámite legislativo se encuentra sometido a un plazo, los efectos de dicho término tendrán directa relación con los efectos previstos en caso de incumplimiento. Estos efectos previstos podrían operar como límite al poder de agenda negativo, en tanto tengan una consecuencia adversa para quienes pretenden impedir o postergar el debate y votación de un proyecto de ley. El efecto sancionatorio que, sin duda, tiene mayor incidencia sobre el poder de agenda en su faz negativa es la aprobación tácita del proyecto no tramitado dentro del plazo fijado. Este efecto otorga al proponente de una iniciativa legislativa una posición privilegiada en su poder de agenda positivo y al resto de los agentes políticos en una posición debilitada para ejercer su poder de agenda negativo.

La Constitución en Chile incluye dos tipos de plazos para la tramitación de la ley: el fijado en el procedimiento de aprobación de la Ley de Presupuestos y la urgencia. El prime-

\footnotetext{
52 Puede tomarse como ejemplo, la moción que propone una reforma constitucional que modifica el artículo $19 \mathrm{~N}^{\circ} 9 \mathrm{CPR}$ para establecer el derecho a la provisión pública de los procedimientos médicos y medicamentos necesarios para conservar y restablecer la salud (Boletín Nº 9142-07 de la Cámara de Diputados). En este proyecto se propone un sistema de provisión de medicamentos de carácter gratuito, financiado con un Fondo Nacional de Medicamentos que recibe aportes del Estado. Sin perjuicio de la naturaleza jurídica de la modificación propuesta, es claro que ella irroga un gasto que si fuese promovido por ley ordinaria, conforme con el artículo $65 \mathrm{CPR}$, solo podría iniciarse por mensaje presidencial.

53 La forma más extendida de plazo legislativo formal es la declaración de trámite urgente. En varias Constituciones de Iberoamérica se otorga al Presidente la facultad de declararlo. Por ejemplo, con distintas modalidades, existen procedimientos urgentes en las Constituciones de Brasil (art. 64), Perú (art. 105), Colombia (art. 163), Ecuador (art. 155), Paraguay (art. 210) y Uruguay (art. 168).

54 Elaboración propia con datos de la Oficinas de Informaciones de ambas cámaras. El período informado corresponde a las legislaturas $35^{\circ}, 355^{\circ}, 356^{\circ}$ y $357^{\circ}$.
} 
ro, de acuerdo al artículo 67, nace con la presentación del proyecto de Ley de Presupuestos por el Presidente y obliga al Congreso a despachar dicha ley dentro de los sesenta días que siguen a su presentación, bajo la sanción de regir la propuesta presidencial en caso de incumplimiento del plazo. La urgencia, por su parte, es una prerrogativa presidencial creada por el artículo 74 de la Constitución, en virtud de la cual, la Cámara debe pronunciarse sobre el proyecto declarado urgente dentro del plazo máximo de treinta días (o menor según dispone de Ley Orgánica Constitucional del Congreso Nacional). Ambos entregan un poder de agenda positivo, de carácter reforzado, al Presidente de la República. Sin embargo, como se explicará, la práctica parlamentaria ha reducido los efectos de dicho poder de un modo ostensible.

El origen del plazo y de la regla de aprobación tácita de la Ley de Presupuestos se encuentra en la Constitución de 1925. En su discusión se sostuvo la importancia de evitar dilaciones en la aprobación de dicha Ley para precaver situaciones como la generada en el período parlamentarista ${ }^{55}$. La aprobación tácita tiene, en principio, un efecto disuasivo sobre el poder de agenda en su faz negativa, por cuanto la dilación en el pronunciamiento del Congreso sobre el proyecto de Ley de Presupuestos puede conducir a la primacía irrestricta de la voluntad presidencial ${ }^{56}$. Notemos que el poder de agenda negativo no desaparece del todo, pues diputados y senadores conservan su facultad de rechazar o disminuir partidas del proyecto presentado, lo que constituye un instrumento de negociación política que puede disminuir la fuerza del privilegio presidencial de la aprobación tácita.

Por otra parte, la urgencia permite al Presidente imponer a las cámaras plazos de debate y pronunciamiento sobre proyectos de ley que van desde los seis hasta los treinta días por trámite parlamentario. Como en el caso de la Ley de Presupuestos, la urgencia tuvo su origen en la mala evaluación de las prácticas legislativas del parlamentarismo, en especial en el abuso del poder de agenda en su faz negativa ${ }^{57}$. La calificación de la urgencia para efectos de la aplicación de uno de los tres plazos previstos por la regulación de la Ley Orgánica Constitucional del Congreso Nacional, corresponde al Presidente de la República. Dicha calificación refuerza el poder del Presidente para erigir la agenda legislativa en su cara positiva, al menos desde un punto de vista teórico, toda vez que dispone de una herramienta que le permite seleccionar el plazo que mejor se ajusta a su interés político. Como es sabi-

\footnotetext{
55 Ministerio del InTERIOR (1926) pp. 66-71, 348-349, 498-499. Se propusieron algunas alternativas para morigerar la regla de aprobación tácita, como por ejemplo, asegurar prioridad al trámite de la Ley de Presupuestos en la Cámara Baja o acotarla a la parte referida a los gastos fijos. Otra opción, sostenida por los partidarios del parlamentarismo, fue eliminar la aprobación tácita, pero dotar al Presidente de la facultad de disolver la Cámara de Diputados. Como parte de la negociación se aceptó que la aprobación tácita solo podía operar en caso de presentación oportuna del proyecto, esto es, seis meses antes de su fecha de entrada en vigencia.

56 Situación observada por Eliodoro Yáñez en la discusión de la regulación de la urgencia en 1925: "si se aceptara lo primero [la aprobación tácita] una minoría podría aprovecharse de esta disposición obstruyendo, a fin de que un proyecto quedara automáticamente aprobado"; Ministerio Del INTERIOR (1926) p. 235.

57 Ministerio del Interior (1926) pp. 230, 234-238. En el debate no solo se consideró el retraso en la tramitación de iniciativas del Presidente, sino que también los problemas generados entre cámaras. Dentro de las propuestas debatidas y desechadas en definitiva, se encuentra la aprobación o rechazo tácito. Se sostuvo que la aprobación o rechazo tácito dañaría la dignidad del Congreso y en este sentido, parecía más viable restringir la facultad a constreñir a las cámaras a pronunciarse sobre el proyecto presentado.
} 
do, la urgencia prevista en el régimen constitucional chileno carece de una sanción en el caso de incumplimiento del plazo previsto, a diferencia de lo previsto en otros ordenamientos jurídicos ${ }^{58}$.

La suma de la carga que imponen a los congresistas el conjunto de proyectos declarados urgentes -en un contexto de tiempo de discusión limitado- y la inexistencia de una sanción jurídica derivada de su incumplimiento, transforma el mandato constitucional del artículo 74 en una feble exigencia de plazo. De hecho, es en extremo poco frecuente que el Presidente obtenga el pronunciamiento de la cámara en el plazo de la urgencia fijado por el ordenamiento jurídico. Así, si se examinan los tiempos de tramitación de mensajes y mociones que han recibido algún tipo de declaración de urgencia, se comprueba que el período total de debate legislativo excede con mucho el previsto en la Constitución. En el período que va desde el 11 de marzo de 2006 al 10 de marzo de 2010, del total de mensajes admitidos a tramitación, debatidos y publicados, que recibieron declaración de algún tipo de urgencia, el promedio de días invertido en su tramitación es de 380, cerca de doce veces el tiempo previsto para los proyectos que tienen declaración de simple urgencia ${ }^{59}$. La misma estadística para el caso de las mociones asciende a 791 días en promedio ${ }^{60}$.

La información disponible permite afirmar que la diferencia observada entre los plazos fijados en normas sobre la urgencia y el tiempo real de tramitación de un proyecto declarado urgente no es coyuntural, sino permanente. Esta distancia entre norma y realidad, un fenómeno que deriva del juego político, tiene su apoyo en normas camarales que relativizan o merman la importancia del plazo fijado por la CPR y la ley, y en la existencia de ámbitos de discrecionalidad procedimental otorgados a autoridades de las cámaras y congresistas. Entre las primeras, pueden mencionarse disposiciones tales como las que otorgan a la simple urgencia una regulación similar a la aplicable a proyectos sin urgencia, la caducidad de las urgencias una vez concluida la legislatura y el poder de los congresistas de dejar sin efecto una norma reglamentaria en un caso particular ${ }^{61}$. Los ámbitos de discrecionalidad procedimental tienen su origen en normas reglamentarias, convenciones y prácticas

\footnotetext{
58 La Constitución uruguaya permite la aprobación tácita por vencimiento del plazo de urgencia, pero tiene restricciones importantes (como número total de urgencias solicitables y tipos de proyectos de ley sobre las que puede recaer). El Congreso puede, además, con un quórum reforzado, dejarla sin efecto (artículo 168). En Brasil y Colombia el principal efecto del incumplimiento del plazo es que el proyecto ingresa de modo forzoso a el orden del día más próximo, desplazando a todo otro asunto (artículos 64 Constitución de Brasil y 163 de la Constitución de Colombia).

59 Contados desde su ingreso en la Oficina de Partes hasta la fecha de remisión al Presidente de la República. La cifra incluye doscientos Mensajes e incluye todo tipo de proyectos de ley y reforma constitucional. Excluye, eso sí, acuerdos internacionales y la Ley de Presupuestos (que suman noventa y cinco Mensajes adicionales). Una cantidad similar es la que exhibe la estadística del período comprendido entre el 11 de marzo de 1990 y el 10 de marzo de 1994: mensajes con algún tipo de urgencia 203 días promedio, mociones con algún tipo de urgencia 633 días; Proyecto de Modernización-Congreso Nacional de Chile (1994) pp. 39 y 74.

60 Las ochenta y ocho Mociones aprobadas y publicadas en el período que no recibieron ningún tipo de urgencia en su tramitación tardaron en su trámite parlamentario un promedio de 859 días. Los nueve Mensajes aprobados y publicados del mismo período que no tuvieron ningún tipo de urgencia tardaron en su trámite parlamentario un promedio de 506 días.

${ }^{61}$ Véase, por ejemplo, el inciso $4^{\circ}$ del art. 190 y el art. 213 del Reglamento de la Cámara de Diputados (en adelante RCD) y el art. 153 del Reglamento DEL SENADo (en adelante RS).
} 
parlamentarias que reconocen a los congresistas un cierto poder de control sobre el trámite del proyecto declarado urgente ${ }^{62}$.

Ahora bien, la debilidad de la urgencia como instrumento para imponer un plazo al trabajo legislativo de las cámaras, no significa que ella carezca de utilidad. Sin duda, tiene sensible relevancia como vehículo de intervención presidencial en la agenda legislativa de las cámaras. Esto por el poder que confiere al Presidente el hecho que los proyectos que reciban la calificación de urgentes tienen preferencia en su tramitación en Sala y comisión.

La preferencia indicada se configura en los reglamentos camarales y se manifiesta con distintas modalidades, según el tipo de urgencia, y no siempre con igual grado de imperatividad. Existen al menos siete tipos de disposiciones reglamentarias que reconocen la preferencia del trámite de proyectos urgentes, a saber: reglas especiales de acceso a las tablas de Sala o comisión ${ }^{63}$; reglas destinadas a convocar sesiones especiales para conocerlos ${ }^{64}$; reglas que entregan preferencia dentro de los asuntos incluidos en la tabla $\mathrm{a}^{65}$; reglas que imponen a la comisión la carga de despachar dentro del plazo otorgado, con la obligación de cerrar el debate y votar el último día del mismo, o bien permiten prescindir del informe de comisión ${ }^{66}$; reglas que suprimen trámites (como eliminación del segundo informe de comisión) ${ }^{67}$; reglas que imponen un procedimiento de discusión abreviado (discusión en general y particular simultanea ${ }^{68}$; y reglas que limitan las atribuciones que pueden ejercer los parlamentarios en el trámite de la ley ${ }^{69}$.

62 Así, por ejemplo, el art. 109 del RCD, después de la reforma de marzo de 2014, dispone que el orden de preferencia que beneficia a los proyectos urgentes opera "[d]e no producirse la situación prevista en el artículo anterior (...)". Dicha situación es que la tabla "será formada por la Mesa y la unanimidad de los Comités Parlamentarios (...)". Luego, si existe tal acuerdo unánime, se puede prescindir de la preferencia de los proyectos urgentes en la tabla, por cierto, respetando los plazos previstos en la CPR y en la LOCCN.

${ }_{63}$ Arts. 192 RCD y 151 RS.

${ }^{64}$ Art. 191 RCD.

${ }_{65}$ En ambas Cámaras los proyectos urgentes tienen preferencia sobre los demás, con excepción de acusaciones constitucionales y la ley de presupuestos (en el Senado el impedimento para votar también tiene mejor preferencia; arts. 109 RCD y $96 \mathrm{RS}$ ). El art. $193 \mathrm{RCD}$ permite a la Mesa dar trámite preferente a un proyecto que en tercer trámite no tiene urgencia, pero sí la tuvo en primer o segundo trámite. En las comisiones de la Cámara, los proyectos con discusión inmediata, suma urgencia y simple urgencia tienen preferencia en la tabla (art. 265 RCD). En el Senado, las comisiones se rigen por las normas especiales del Título IV y, a falta de estas, por las normas generales del RS (art. $31 \mathrm{RS}$ ), lo que también conduce a una preferencia.

${ }^{66}$ Arts. 187,188 y 190 RCD y 147 RS.

67 Arts. 188 y 189 RCD y 147,148 y 150 RS.

68 Los proyectos con suma urgencia y discusión inmediata en la Cámara y los con discusión inmediata en el Senado, unen la discusión general y particular (arts. 188, 189 y 134 RCD y art. 150 RS). Esto genera reglas especiales de discusión y votación (arts. 85, 142, 230 y 233 del RCD y 152 RS).

69 En el Senado la preferencia también se expresa en la imposibilidad de pedir el retiro de un proyecto urgente de la tabla de fácil despacho (art. 88 RS) y, en los casos de proyectos con discusión inmediata o suma urgencia, la improcedencia de pedir el aplazamiento de discusión ante el incumplimiento de las exigencias del art. 116 RS. La primera, propia de la Cámara de Diputados, es que las indicaciones rechazadas recaídas en proyecto con urgencia solo pueden ser renovadas si cuentan con el apoyo de treinta diputados (los que deben incluir a tres jefes de Comités), lo que dificulta su formulación y, en principio, contribuye a favorecer la velocidad de tramitación de iniciativas urgentes (art. 190 RCD). 
La suma de las consideraciones anteriores sugiere que el poder presidencial derivado de la facultad de declarar la urgencia para el trámite de un proyecto de ley, en sus distintos grados, consiste en ubicar los proyectos urgentes en las tablas de sesiones de Sala y comisión y disfrutar de un cierto grado de preferencia para el debate y votación de los mismos. Esta preferencia no asegura que el proyecto será debatido y votado, ya que la aplicación de disposiciones reglamentarias, convenciones o prácticas parlamentarias puede transformarla en una primacía más bien formal. Es el consenso de los órganos directivos de ambas cámaras y de los congresistas el que impulsa la renuncia al poder de agenda en su faz negativa y hace operativa la preferencia indicada. Este consenso es del mismo tipo que aquel que permite entender que mociones que carecen de urgencia reciban aprobación parlamentaria en plazos que, incluso en unos pocos casos, son más breves que los que han recibido proyectos que han tenido algún tipo de urgencia.

\subsubsection{El poder de agenda en relación con el procedimiento parlamentario}

Las facultades presidenciales en el procedimiento legislativo intracameral, distintas de la potestad de declarar la urgencia y la de presentar Mensajes en el campo de su iniciativa exclusiva, son más bien limitadas. Si bien el Presidente de la República puede intervenir en los debates por medio de sus ministros y, si lo estima pertinente, presentar indicaciones, su capacidad para imponer o promover la tramitación expedita de una iniciativa es débil ${ }^{70}$.

La aplicación del principio de separación poderes justifica que el Presidente de la República carezca de facultades para intervenir en un conjunto de actos y decisiones parlamentarias de carácter procedimental que inciden en la duración total del trámite de un proyecto de ley. Por lo mismo, dicho conjunto de actos y decisiones parlamentarias tienden a generar un poder de agenda negativo significativo para diputados y senadores, ya que no es difícil, en uso de normas de procedimiento, paralizar o hacer más lento el trámite de una iniciativa de ley. En la práctica, el reconocimiento de un conjunto de atribuciones a los parlamentarios individuales o a la Sala, asociado a la aptitud de dichas atribuciones para ralentizar el curso del trámite, constituye un importante incentivo para la generación de consensos - procedimentales y sustantivos- entre quienes tienen un interés en el debate y aprobación de un proyecto de ley y quienes carecen de dicho interés. En tanto el Presidente de la República requiere de la aprobación de leyes para ejecutar su programa de gobierno, deberá generar el consenso político que asegure que el poder de agenda negativo de los parlamentarios no constituirá un obstáculo para alcanzar los resultados legislativos que su mandato popular exige.

Ahora bien, la identificación de las atribuciones procedimentales que tienen mayor incidencia potencial en la ralentización del trámite legislativo no es sencilla, pues se trata de facultades que adquieren o pierden relevancia de un modo dinámico de acuerdo con las necesidades y condiciones de funcionamiento del sistema político. Las atribuciones procedimentales que pueden ser útiles para retrasar o acelerar el trámite legislativo de los proyectos de interés presidencial constituyen una herramienta central en la distribución de poder po-

70 El Presidente de la República tiene una limitada ventaja procedimental en el artículo 35 de la LOC CN: la votación de sus observaciones solo puede aprobarlas o rechazarlas, pero no dividirlas. 
lítico que opera en los ejes Presidente-Congreso Nacional y Gobierno-Oposición y por lo mismo son funcionales a los cambios que experimenten las instituciones y los partidos políticos. Con todo, conviene notar que aun cuando, ab initio, los parlamentarios tengan una posición ventajosa en el terreno que analizamos, lo cierto es que el uso del poder de agenda negativo solo tiene éxito en aquellos casos en que incentiva una negociación sustantiva, ya que fracasa si paraliza el curso del trámite legislativo o lo lentifica y, como consecuencia, el Presidente opta por seguir otros caminos para alcanzar el cambio que promueve.

En los párrafos que siguen presentaremos algunas cuestiones procedimentales generales y particulares que pueden ser útiles para dimensionar el alcance del poder parlamentario en las decisiones que inciden tanto en la velocidad de tramitación como en el éxito o fracaso de mociones y mensajes. Distinguiremos dos facultades generales y luego revisaremos algunas competencias procedimentales de los parlamentarios en particular.

La primera facultad general que beneficia a los congresistas es la facultad de los diputados y senadores de no aplicar una disposición reglamentaria si existe acuerdo para ello. Según el RCD y el RS, salvo norma expresa en sentido contrario, en un caso o asunto particular puede suspenderse el cumplimiento de un precepto reglamentario por acuerdo unánime de los Comités Parlamentarios ${ }^{71}$. Esta prerrogativa permite a los parlamentarios introducir cambios en el trámite legislativo regulado (v. gr. prorrogar un plazo) prolongando o abreviando el proceso de debate y aprobación de un mensaje o moción.

En segundo lugar, es necesario considerar las facultades directivas del Presidente de la Cámara, la Mesa y los Jefes de Comité para evaluar el poder de los congresistas y las cámaras en materia de procedimiento, ya que su ejercicio tiene gran incidencia en la velocidad del trámite legislativo ${ }^{72}$. En efecto, dependiendo de la atribución que se trate, las decisiones o propuestas del órgano directivo pueden facilitar o complejizar el trámite de una moción o mensaje. El ejercicio de dichas facultades suele someterse o ceñirse a las prioridades de la mayoría, lo que tiene directa relación con la potestad de la Sala para imponer su voluntad en uso de su competencia resolutiva final ${ }^{73}$. La posición de la mayoría y, en su caso, de la minoría, es relevante como sustrato de las decisiones procedimentales adoptadas por los órganos directivos de ambas Cámaras. Si no existe consenso en la decisión de dar

\footnotetext{
71 Arts. 23 RCD y 17 RS. En el caso de la Cámara de Diputados también por acuerdo unánime de los diputados. Con todo, la regla general es que el Reglamento solo puede modificarse con las formalidades necesarias para la tramitación de un proyecto de ley (arts. 217 RS y 24 RCD).

${ }^{72}$ La mayoría parlamentaria y sus líderes disponen de las herramientas de gobierno cameral para acelerar o frenar el trámite de una moción o mensaje. Hasta cierto punto, también pueden acceder a estas herramientas las autoridades de la cámara (sin el necesario respaldo de la mayoría) y la minoría, en tanto la convivencia y la conveniencia política haya generado una convención o práctica parlamentaria al respecto.

73 De todos modos, en la Cámara y Senado, las decisiones adoptadas por la unanimidad de los comités en ejercicio de sus facultades no pueden ser revertidas por la Sala. El art. 62 RCD dispone que ningún diputado podrá oponerse a los acuerdos a que hayan llegado los comités parlamentarios con el Presidente de la Cámara, cuando hayan sido adoptados por todos ellos y por unanimidad. El art. 19 RS dispone que ningún senador podrá oponerse a los acuerdos adoptados por la unanimidad de los comités en cuestiones de su competencia. Esta unanimidad permite utilizar un conjunto de medidas reglamentarias para dar prioridad al trámite de una determinada iniciativa, sin que un parlamentario pueda obstruir dicha prioridad. La necesidad de consenso para este tipo de decisiones, en cierto sentido, incentiva acoger los intereses procedimentales de las distintas bancadas en el mismo o en otros trámites.
} 
curso o acelerar el trámite de un proyecto de ley, la correspondiente decisión directiva será cuestionada por la Sala o bien su implementación enfrentará todas dificultades procedimentales que puedan generar los congresistas que no la apoyan, en uso de sus atribuciones.

El trámite de toda iniciativa legislativa se somete a un conjunto de reglas procedimentales que conforman distintas vías o caminos preestablecidos. Cuando un órgano directivo o la Sala optan por un determinado camino procedimental incrementan o disminuyen la probabilidad de una tramitación más o menos veloz, en armonía con el incremento o disminución del poder de agenda positivo y negativo que los congresistas y los órganos camarales reciben desde las normas que forman parte del estatuto particular escogido. Lo anterior no impide sostener que el camino más expedito surge desde un consenso extendido que cubre lo procedimental y sustantivo, en tanto el camino más lento -o el fracaso de la iniciativa- deriva de un consenso más frágil o inexistente que induce a congresistas que no forman parte de él a la utilización de normas procedimentales en desmedro del progreso del trámite.

Aunque las decisiones procedimentales que permiten que un proyecto se debata y vote son numerosas, debe tenerse presente que solo una parte de las normas que las fundan generan -para congresistas u órganos parlamentarios- la posibilidad de retrasar o acelerar de modo importante el trámite de un mensaje o moción. Sin pretender la elaboración de un listado exhaustivo de las decisiones procedimentales que podemos considerar críticas para el trámite legislativo, es posible destacar algunas de las cuestiones de procedimiento más relevantes que se plantean durante el proceso de formación de la ley en los siguientes ámbitos: admisibilidad, programación, celebración de la sesión, trámite de indicaciones, debate y votación.

La admisibilidad de una moción, mensaje o indicación a trámite es una competencia que pertenece al Presidente de la Cámara o de la Comisión. Como señalamos antes, su ejercicio puede ser revisado por la Sala (o, si se quiere, por la mayoría parlamentaria $)^{74}$. Esta facultad sirve para controlar el cumplimiento de las normas de la iniciativa exclusiva, como también la aplicación del origen reservado del artículo 65 y la regla de atingencia de los artículos 69 y 73 CPR. Observemos que si el mensaje o moción es declarado inadmisible por el Presidente de la Cámara o de la Comisión, o por la mayoría parlamentaria, en su caso, su trámite se detendrá por completo aun cuando el fundamento jurídica que sustente dicha declaración sea débil o inexistente ${ }^{75}$. Asimismo, la inadmisión de una indicación, en principio, la excluye del proceso de debate.

\footnotetext{
74 Arts. 15, 24 y 25 LOC CN; 14, 55 No 2, 130, 168, 244 No 16 y 274 RCD; y 80, 118, 120, 121, 122, 124, 126, 131, 166 RS.

75 La posibilidad de recurrir al Tribunal Constitucional no impide el retraso, pues de todos modos habrá que invertir tiempo y recursos en la construcción de un argumento jurídico como cuestión previa al inicio de la tramitación efectiva de la Moción o Mensaje. Hay dos fallos del Tribunal Constitucional recaídos en declaraciones de inadmisibilidad (SSTC 464/06 y 2646/14). En el segundo, el Presidente de la Cámara declaró la inadmisibilidad de once observaciones presidenciales sobre la base de un acuerdo de las comisiones unidas de Constitución, Legislación y Justicia y Obras Públicas, Transporte y Telecomunicaciones, al que se suma un acuerdo entre bancadas. El Presidente de la Cámara sostuvo que la Constitución no exige fundar dicha declaración y que ella no es susceptible de control de constitucionalidad. En ambos fallos el Tribunal declara que se trata de un asunto
} 
Después de la admisión del proyecto y antes de dar cuenta a la Sala, la autoridad parlamentaria competente debe proponer el tipo de trámite y discusión que recibirá la iniciativa presentada, lo que incluye la decisión acerca de la comisión o comisiones que conocerán del proyecto, como también, en el caso que sean varias, la modalidad con que ellas estudiarán e informarán el proyecto (de manera reunida, sucesiva u otra) ${ }^{76}$. Sin perjuicio de la facultad de la Sala de introducir cambios a la propuesta del órgano competente, el camino trazado por esta vía tiene una significativa incidencia en el tiempo que se destinará al debate y aprobación de la iniciativa de ley. Así, por ejemplo, proponer el estudio sucesivo de un proyecto por dos o tres comisiones, o el orden fijado para dicho estudio y debate, o la decisión de remitir un proyecto a una comisión que tiene ya varias iniciativas en trámite, o la inclusión de un proyecto en la tabla de fácil despacho, o la adopción de la modalidad de discusión en general y particular a la vez, o la discusión por ideas, afectará de modo sensible el tiempo total de tramitación del proyecto.

Una vez fijado el curso que seguirá el trámite del proyecto, este debe ser incluido en el orden del día para que sea debatido en Sala o comisión. Ambos reglamentos camarales tienen reglas para la conformación de dicho orden pero tanto las facultades de los órganos directivos de las cámaras como la superposición de más de un iniciativa con declaración de urgencia, generan un ámbito de decisión discrecional que ampara la priorización que nace de circunstancias y criterios políticos y partidistas ${ }^{77}$.

La inclusión de una iniciativa en el orden del día de Sala o comisión no asegura su debate y votación en la misma. Por lo pronto, en el caso de la Sala, la discusión podría quedar aplazada para la sesión siguiente si los documentos pertinentes no han sido distribuidos oportunamente $^{78}$. En el caso de las comisiones, la sesión pertinente debe ser citada por su Presidente y su celebración y funcionamiento depende de la existencia del quórum para sesionar y del quórum para adoptar decisiones ${ }^{79}$. Los parlamentarios, en uso de su poder de agenda negativo, podrían no asistir a la sesión convocada y, por esta vía, impedir su celebración, retrasando el trámite del proyecto incluido en el orden del día.

de naturaleza legal. La STC 2025/11, por otros caminos, afirma la competencia del Tribunal en una cuestión de tramitación de la ley que involucra a una norma reglamentaria.

76 Arts. 55 No 3 RCD y 27, 28, 79 RS.

77 El orden del día sigue la fecha de ingreso y otorga preferencia a los proyectos con declaración de urgencia, sin perjuicio de la primacía en la Cámara de las decisiones adoptadas por la unanimidad de la Mesa y los comités (arts. 108 y 109 RCD y 96, 92 y 151 RS). El artículo 93 RS otorga preferencia también a los proyectos que han avanzado más en su trámite, en los términos previstos por su texto. En el Senado el orden del día puede modificarse por acuerdo de comités que representen a las dos terceras partes de los senadores en ejercicio (art. $94 \mathrm{RS}$ ) y por acuerdo unánime de la Sala puede incluso agregarse asuntos que no están incluidos en él (art. 95 RS).

78 Art. 116 RS, a menos que se trate de proyectos con suma urgencia o discusión inmediata.

79 Recordemos que, por regla general, las comisiones no pueden sesionar mientras lo esté haciendo la Sala. Si bien el Presidente convoca, existen además otras regla de convocatoria (Sala, comités o autoconvocatoria). En la Cámara se exige la concurrencia de la tercera parte de sus miembros en ejercicio para sesionar y adoptar acuerdos (art. 8 RCD) y en el Senado la mayoría de sus miembros (art. 33 RS). En la Cámara Alta si no hay quórum para sesionar pasados quince minutos de la hora fijada para el inicio de la sesión, el secretario a petición de cualquier integrante de la comisión declarará que la sesión no se celebra. 
Una vez que ha comenzado el debate del proyecto, la duración del mismo depende de varias cuestiones asociadas a su contenido (su complejidad, extensión, relevancia política, económica o social) como también de decisiones adoptadas por los parlamentarios para su estudio (como la comparecencia de autoridades del Poder Ejecutivo, la invitación a expertos y la celebración de audiencias públicas, entre otras). En esta cuestión tiene especial relevancia el plazo que fija la Sala para evacuar el informe de comisión, término que guiará la programación de sesiones para el debate de la iniciativa.

Asimismo, tiene especial incidencia en el progreso del debate la regulación de las indicaciones y las decisiones parlamentarias adoptadas a su respecto. Los plazos fijados para presentarlas pueden ser más o menos extensos y, por lo mismo, incentivar o desincentivar la discusión en particular de una iniciativa ${ }^{80}$. También el régimen de las indicaciones desechadas tiene importancia, ya que la existencia de algunas restricciones a su renovación en Sala permite simplificar la discusión particular ${ }^{81}$. Asimismo, en el Senado, la aprobación de indicaciones por la unanimidad de los miembros de la comisión informante permite que ellas se voten sin debate previo en la Sala ${ }^{82}$.

El tiempo destinado al debate de un proyecto se encuentra regulado en términos de su duración total y en la cuota que corresponde a cada bancada o comité. Este tiempo puede extenderse o abreviarse de acuerdo a los procedimientos y convenciones parlamentarias vigentes. Una mayoría simple, eso sí, puede solicitar la clausura del debate, la que de ser aprobada fuerza someter a votación el proyecto de que se trate.

Por último, en el curso del debate algunos procedimientos previstos en los reglamentos camarales podrían, a solicitud de uno o más parlamentarios, extender el debate de una iniciativa legislativa. A modo de ejemplo, en ciertos casos puede proponerse el aplazamiento temporal de la consideración del asunto, una segunda discusión, una segunda votación, la reapertura del debate, una nueva remisión a comisión, etc. ${ }^{83}$.

\footnotetext{
80 La Sala debe fijar un plazo para recibir indicaciones si un comité lo solicita. Las comisiones también pueden fijar un plazo para la formulación de indicaciones. Si se pone suma urgencia a una iniciativa no se admiten indicaciones.

81 Las indicaciones rechazadas pueden ser renovadas (por el Presidente de la República, comités o un cierto número de congresistas. No siempre la renovación de indicaciones rechazadas es posible (por ejemplo, si fueron declaradas inadmisibles en la Comisión, de acuerdo al art. 24 RS). También se imponen restricciones a la votación de indicaciones renovadas.

82 Art. 133 RS.

83 En el Senado, al iniciarse la discusión particular, el Presidente puede dar por aprobados todos los artículos que no hayan sido objetos de indicación en la discusión general o de modificación en el segundo informe. Sin embargo, un senador apoyado por la unanimidad de los presentes, puede revivir la discusión de uno o más artículos o títulos (art. 124 RS). La reapertura del debate se regula en el art. 125 RS y la segunda discusión en el art. 129.
} 


\section{CONSIDERACIÓN FINAL}

La crítica al presidencialismo como sustento de un régimen democrático estable explicita una combinación de supuestos políticos y estructuras constitucionales que propician conflictos insalvables entre el Presidente y el Congreso. Dicho análisis crítico se suma, en el caso de Chile, al diagnóstico que revela el aumento de las potestades constitucionales del Presidente de la República en desmedro de las facultades del Congreso Nacional. Si a tales elementos adicionamos un Congreso dividido, las probabilidades de sustentar un régimen democrático estable, en el papel, decaen de un modo manifiesto. Sin embargo, el régimen presidencialista chileno, desde 1990 puede exhibir como resultado veinticinco años de una democracia que, pese a sus deficiencias, funciona de modo aceptable.

El funcionamiento del régimen democrático y constitucional vigente solo puede explicarse sobre la base de cierto grado de colaboración entre Presidente y Congreso, y ello ha sido reconocido por la doctrina antes citada. En este trabajo, dada la relevancia política de la función, el análisis de la relación de colaboración se ha concentrado en el proceso legislativo y, en particular, en la formación de la agenda legislativa. En este terreno, la colaboración entre los poderes colegisladores no es fácil de armonizar con la posición de primacía jurídica que la Constitución otorga al Presidente y que ha sido subrayada también por la doctrina. Si el Presidente de la República cuenta con poderes legislativos exorbitantes, sería predecible que ante una discrepancia política con el Congreso hiciera uso de ellos en su propio beneficio, forzando la adopción de decisiones legislativas favorables o, como plantean los críticos del presidencialismo, dando pie a un bloqueo del proceso legislativo.

La colaboración observada entre poderes colegisladores tiene al menos dos sustratos o apoyos. El primero, político y partidista, no ha sido estudiado en este trabajo. Sin embargo, es posible intuir que las lecciones provenientes de la historia reciente del país, han sido determinantes para fijar el contenido de las decisiones de gobierno y para establecer el cómo se ejercen las atribuciones constitucionales de los órganos políticos. El segundo es el jurídico procedimental que, mediante normas y convenciones, encauza el ejercicio de las potestades legislativas del Presidente y del Congreso incentivando o forzando la cooperación entre los intervinientes en el proceso legislativo.

En la dimensión jurídico-procedimental nuestra tesis central es que las potestades constitucionales del Presidente del República en lo relacionado con la formación de la agenda legislativa se han visto relativizadas y morigeradas como consecuencia de un conjunto de normas legales y reglamentarias, complementadas por convenciones y prácticas parlamentarias $^{84}$. Dicho conjunto de reglas erige una especie de estructura que induce o fuerza la colaboración entre poderes colegisladores, lo que a su vez promueve un acomodo de intereses políticos diversos y distancia la relación política de la opción del bloqueo legislativo. Aunque el Presidente sigue siendo el claro protagonista del proceso decisorio que da origen a la ley, es palmario también que la posición del Congreso y de diputados y senadores en la formación de la ley es de especial influencia, en particular, en lo referido a la selección de materias que serán objeto de regulación legal.

84 Berríos y Gamboa (2006) p. 100. 
La estructura jurídico-procedimental que hemos intentado describir aquí y que sustenta la cooperación y negociación entre los poderes colegisladores, no solo es índice de la mayor capacidad actual de los parlamentarios de influir en el proceso legislativo. También constituye una construcción de carácter permanente que regula y condiciona el futuro de las relaciones entre Presidente y Congreso en el proceso de formación de la agenda legislativa. No parece posible modificar el equilibrio político que tales reglas suponen, sino con cambios jurídicos y políticos significativos.

Por último, cabe notar que, sin negar los aspectos críticos del presidencialismo -los que fueron comentados en el inicio de este trabajo- es posible sostener que una suma de factores políticos y jurídicos no recogidos ni formalizados en el texto constitucional puede incidir de modo permanente en su funcionamiento. Tales factores pueden inducir la búsqueda de un consenso legislativo de un modo en que las prerrogativas presidenciales que amenazan el equilibrio entre los poderes políticos resultan disminuidas hasta un nivel compatible con una efectiva legitimidad democrática dual.

\section{BIBLIOGRAFÍA CITADA}

Agor, Weston (1971): Latin American Legislatures: Their Role and Influence, Analysis for Nine Countries (New York, Praeger).

Alcántara Sáez, Manuel y Sánchez López, Francisco (2001): “Las relaciones EjecutivoLegislativo en América Latina: Un análisis de la estructura de veto-insistencia y control político", Revista de Estudios Políticos, No 112 Nueva Época: pp. 53-76.

Alemán, Eduardo y Schwartz, Thomas (2006): "Presidential vetoes in Latin American Constitutions", Journal of Theoretical Politics, No 18 (1): pp. 98-120.

Altman, David (2008): "Régimen de gobierno y sistema de partidos en Chile", en FontaIne, Arturo; Larroulet, Cristián; Navarrete, Jorge; y Walker, Ignacio (eds.), Reforma de los partidos políticos en Chile (Santiago, PNUD, CEP, Libertad y Desarrollo, Proyectamerica, CIEPLAN) pp. 41-74.

Aninat, Cristóbal (2006): "Balance de poderes legislativos en Chile. ¿Presidencialismo exagerado o base de un sistema político cooperativo?”, Política Revista de Ciencia Política, No 47: pp. 127-148.

Arriagada, Genaro y Godoy, Oscar (1992): Cambio de Régimen Politico (Santiago, Ediciones Universidad Católica de Chile).

Berríos, Fabiola y Gamboa, Ricardo (2006): "El Congreso Nacional chileno y el ejercicio de sus funciones legislativa y fiscalizadora", Politica Revista de Ciencia Política, No 47: pp. 99-125.

Blondel, Jean y SuÁreZ, Waldino (1981): "Las limitaciones institucionales del sistema presidencialista”, Criteria, No 1853, vol. 54: pp. 57-70.

Boeninger, Edgardo (2008): "Relaciones entre partidos, Gobierno y Parlamento en el sistema presidencial chileno", en Fontaine, Arturo; Larroulet, Cristián; Navarrete, Jorge; y Walker, Ignacio (eds.), Reforma de los partidos políticos en Chile (Santiago, PNUD, CEP, Libertad y Desarrollo, Proyectamerica, CIEPLAN) pp. 191-219. 
Bravo Lira, Bernardino (2010): Constitución y reconstitución. Historia del Estado en Iberoamérica 1511-2009 (Santiago, Abeledo Perrot).

Bronfman, Alan (2012): "La evaluación de la ley", 50 + Uno - Revista Chilena de Derecho Parlamentario, No 1: pp. 74-88.

Bulnes Ripamonti, Cristian (1967): Relaciones y conflictos entre los órganos del poder estatal (Santiago, Editorial Jurídica de Chile).

CARpizo, Jorge (2007): Concepto de democracia y sistema de gobierno en América Latina (México D. F., Instituto de Investigaciones Jurídicas-Universidad Nacional Autónoma de México).

Cea Egaña, José Luis (2002): Derecho Constitucional Chileno, Tomo I (Santiago, Ediciones Universidad Católica).

Cheibub, José Antonio (2007): Presidentialism, Parlamentarism and Democracy (Cambridge, Cambridge University Press).

Cheibub, José Antonio (2002): "Presidentialism and Democratic Performance", en ReyNOLDS, Andrew, The Architecture of Democracy (Oxford, Oxford University Press) pp. 104-140.

Cheibub Figueiredo, Argelina y Limongi, Fernando (2000): "Presidential Power, Legislative Organization, and Party Behavior in Brasil", Comparative Politics, vol. 32 No 2: pp. 151-170.

Cordero Quinzacara, Eduardo (2010): "La legislación delegada en el derecho chileno y su función constitucional”, Revista de Estudios Constitucionales, Año 8 No 2: pp. 49-86.

Cordero Quinzacara, Eduardo (2009): "El sentido actual del dominio legal y la potestad reglamentaria", Revista de Derecho de la Pontificia Universidad Católica de Valparaíso, XXXII: pp. 409-440.

Cox, Gary W. y McCubbins, Mathew D. (2005): Setting the Agenda (Cambridge, Cambridge University Press).

Cox, Gary y Morgenstern, Scott (2002): "Epilogue: Latin America’s Reactive Assemblies and Proactive Presidents”, en Morgenstern, Scott y Nacif, Benito (eds.), Legislative Politics in Latin America (Cambridge, Cambridge University Press) pp. 446-468.

Cumplido, Francisco (1970): “La especificación de la ley”, en Frei, Eduardo; Lagos, Gustavo; Molina, Sergio; Silva, Alejandro; Evans, Enrique y Cumplido, Francisco, Reforma constitucional 1970 (Santiago, Editorial Jurídica de Chile) pp. 179-195.

Chasquetti, Daniel (2001): "Democracia, multipartidismo y coaliciones en América Latina: evaluando la difícil combinación”, en LANZARO, Jorge (comp.), Tipos de presidencialismo y coaliciones políticas en América Latina (Buenos Aires, Clacso) pp. 319-359.

Eizenstat, Stuart E. (1990): "The State of the Modern Presidency: Can It Meet Our Expectations", Occasional Papers from The Law School The University of Chicago, No 26: pp. 1-29.

Gamboa Valenzuela, Ricardo (2005): "Las relaciones entre los poderes Ejecutivo y Legislativo en el presidencialismo latinoamericano y chileno. Un análisis crítico de la literatura”, Revista de Derecho Público, No 67: pp. 59-72. 
Garretón, Manuel Antonio (2001): "La cuestión del régimen de gobierno en el Chile de hoy", en Lanzaro, Jorge (comp.), Tipos de presidencialismo y coaliciones políticas en América Latina (Buenos Aires, Clacso) pp. 189-202.

Garretón, Manuel Antonio (1990): "La posibilidad democrática en Chile: condiciones y desafíos”, en Stuven, Ana María (edit.), Democracia contemporánea. Transición y consolidación (Santiago, Ediciones Universidad Católica de Chile) pp. 177-190.

Geisse, Francisco y Ramírez Arrayas, José Antonio (1989): La reforma constitucional (Santiago, CESOC-Ediciones Chile América).

GIL, Federico (1966): The Political System of Chile (Boston, Hougton Mifflin Co.).

Godoy, Oscar (2003): "Parlamento, presidencialismo y democracia protegida", Revista de Ciencia Política, vol. XXIII No 2: pp. 7-42.

Godoy, Oscar (1990): “El régimen parlamentario: una opción política para Chile”, en Linz, Juan; Lijphart, Arend; Valenzuela, Arturo; Godoy Arcaya, Oscar (eds.), Hacia una democracia moderna. La opción parlamentaria (Santiago, Ediciones Universidad Católica de Chile) pp. 9-39.

Larraín, Manuel (2014): “Oposición política e institucionalidad para el rol opositor en un régimen presidencial de gobierno”, Revista de Derecho Público, No 81: pp. 123-139.

LIjpharT, Arend (1994): "Presidentialism and Majoritarian Democracy: Theoretical Observations", en Linz, Juan J. y Valenzuela, Arturo (eds.), The Failure of Presidential Democracy. Comparative Perspectives vol. 1 (Baltimore, John Hopkins University Press) pp. 91-105.

Lijphart, Arend; Rogowski, Ronald y Weaver, Kent (1993): "Separation of Powers and Cleveages Management”, en Weaver, Kent y Rockman, Bert (eds.), Do Institutions Matter? Government Capabilities in the United States and Abroad (Washington D. C., Brookings Institution) pp. 302-344.

Linz, Juan; Lijphart, Arend; Valenzuela, Arturo; Godoy Arcaya, Oscar (eds.) (1990): Hacia una democracia moderna. La opción parlamentaria (Santiago, Ediciones Universidad Católica de Chile).

Linz, Juan J. (1994): "Presidential or Parliamentary Democracy: Does It Make a Difference”, en Linz, Juan J. y Valenzuela, Arturo (eds.), The Failure of Presidential Democracy. Comparative Perspectives vol. 1 (Baltimore, John Hopkins University Press) pp. 3-87.

Monsalve, Sofía y SotToli, Susana (1998): "Ingeniería constitucional versus institucionalismo histórico-empírico: enfoque sobre la génesis y la reforma de las instituciones políticas", en Nohlen, Dieter y Fernández, Mario (eds.), El presidencialismo renovado. Instituciones y cambio político en América Latina (Caracas, Nueva Sociedad) pp. 41-55.

Morgenstern, Scott (2002): "Explaining Legislative Politics in Latin America", en Morgenstern, Scott y Nacif, Benito (eds.), Legislative Politics in Latin America (Cambridge, Cambridge University Press) pp. 413-445.

Nogueira Alcalá, Humberto (1986): Análisis crítico del presidencialismo y consideraciones sobre una alternativa de régimen semi-presidencial para Chile (Santiago, Instituto Chileno de Estudios Humanísticos).

Nohlen, Dieter (2013): "El Presidencialismo comparado", Revista del Instituto de Altos Estudios Europeos, № 1: pp. 6-23. 
Nohlen, Dieter y Fernández, Mario (1998): "El presidencialismo latinoamericano: evolución y perspectivas”, en Nohlen, Dieter y Fernández, Mario (eds.), El presidencialismo renovado. Instituciones y cambio político en América Latina (Caracas, Nueva Sociedad) pp. 111-125.

Nohlen, Dieter (1998b): "Presidencialismo versus parlamentarismos: dos enfoques contrapuestos”, en Nohlen, Dieter y Fernández, Mario (eds.), El presidencialismo renovado. Instituciones y cambio político en América Latina (Caracas, Nueva Sociedad) pp. 15-25.

Nohlen, Dieter (1998c): "Sistemas de gobierno: perspectivas conceptuales y comparativas”, en Nohlen, Dieter y Fernández, Mario (eds.), El presidencialismo renovado. Instituciones y cambio político en América Latina (Caracas, Nueva Sociedad) pp. 85-109.

Nolte, Detlef (2003): "El Congreso chileno y su aporte a la consolidación democrática en perspectiva comparada", Revista de Ciencia Política, vol. XXIII No 2: pp. 43-67.

Norton, Philip (1990): "Parliaments. A framework for Analysis" en Western European Politics, No 3: pp. 1-9.

NúŃEz Ramírez, Fernanda (2015): “Taxonomía de la legislación delegada en Chile en el período 1990-2014” Memoria para optar al grado de Licenciado en Ciencias Jurídicas, Escuela de Derecho Pontificia Universidad Católica de Valparaíso.

Olson, David M. (1994): Democratic Legislative Institutions. A Comparative View (Armonk, M E Sharpe Publishers).

Ribera Neumann, Teodoro (2001): "Reserva legal, potestad reglamentaria y Constitución de 1980", Revista de Derecho Público, vol. 63 t. I: pp. 471-488.

Riggs, Fred W. (2004): "Presidentialism: A Problematic Regime Type", en Lijphart, Arend (edit.), Parliamentary versus Presidential Government (Oxford, Oxford University Press) pp. 217-222.

Russell, Meg y Benton, Meghan (2009): "Assessing the Policy Impact of Parliament: Methodological Challenges and Possible Future Approaches” Disponible en: https:// www.ucl.ac.uk/constitution-unit/research/parliament/policy-impact/policy_impact_ parliament.pdf

Schattschneider, E. E. (1960): The Semisovereign People. A Realist's View of Democracy in America (Hinsdale, Illinois, Dryden Press).

Shugart, Matthew Soberg y Carey, John M. (2009): Presidents and Assemblies. Constitutional Design and Electoral Dynamics (Cambridge, Cambridge University Press).

Shugart, Matthew y Carey, John (1992): Presidents and Assemblies. Constitutional Design and Electoral Dynamics (Cambridge, Cambridge University Press).

Siavelis, Peter (2002): "Exaggerated Presidentialism and Moderate Presidents: ExecutiveLegislative Relations in Chile", en Morgenstern, Scott y Nacif, Benito (eds.), Legislative Politics in Latin America (Cambridge, Cambridge University Press) pp. 79-113.

Stein, Ernesto; Tommasi, Mariano; Echebarría, Koldo; Lora, Eduardo; Payne, Mark (coords.) (2006): La política de las políticas públicas. Progreso económico y social en América Latina. Informe 2006 (México, BID, David Rockefeller Center for Latin American Studies, Harvard University, Planeta). 
Stepan, Alfred y SkaCh, Cindy (1993): "Constitutional Framework and Democratic Consolidation: Parliamentarism versus Presidentialism”, World Politics, vol. 46 No 1: pp. $1-22$.

Silva Bascuñán, Alejandro (1970): "El nuevo régimen de iniciativa exclusiva del Ejecutivo", en Frei, Eduardo; Lagos, Gustavo; Molina, Sergio; Silva, Alejandro; Evans, Enrique y Cumplido, Francisco, Reforma constitucional 1970 (Santiago, Editorial Jurídica de Chile) pp. 89-107.

Silva Bascuñán, Alejandro (1963): Tratado de Derecho Constitucional, Tomo III (Santiago, Editorial Jurídica de Chile).

Soto Velasco, Sebastián (2015): "El veto presidencial y el Tribunal Constitucional”, en Anuario de Derecho Público 2015 Universidad Diego Portales (Santiago, Ediciones Universidad Diego Portales) pp. 201-221.

TAPiA VAldés, Jorge (1960): La Técnica Legislativa (Santiago, Editorial Jurídica de Chile).

ThiBAut, Bernhard (1998): "El gobierno de la democracia presidencial: Argentina, Brasil, Chile y Uruguay en una perspectiva comparada”, en Nohlen, Dieter y Fernández, Mario (eds.), El presidencialismo renovado. Instituciones y cambio político en América Latina (Caracas, Nueva Sociedad) pp 127-150.

Toro Maureira, Sergio y García Grandón, Daniela (2008): "Mecanismos de selección de candidatos para el Poder Legislativo: un examen a las lógicas de mayor y menor inclusión”, en Fontaine, Arturo; Larroulet, Cristián; Navarrete, Jorge; y Walker, Ignacio (eds.), Reforma de los partidos políticos en Chile (Santiago, PNUD, CEP, Libertad y Desarrollo, Proyectamerica, CIEPLAN) pp. 395-412

Tsebelis, George (2002): Veto Players. How Political Institutions Work (Princeton, Russell Sage Foundation).

Valencia Carmona, Salvador (1979): El Poder Ejecutivo Latinoamericano (México, UNAM).

Valenzuela, Arturo (2004): "Latin American Presidencies Interrupted", Journal of Democracy, vol. 15 No 4: pp. 5-19.

WALKer, Jack L. (1977): "Setting the Agenda in the U. S. Senate: A Theory of Problem Selection”, British Journal of Political Science, vol. 7 No 4: pp. 423-445.

\section{DOCUMENTOS}

Departamento de informaciones del Senado (2013): Sintesis Legislativa No 55 (disponible en www.senado.cl).

Ministerio del Interior (1926): Actas Oficiales de las Sesiones celebradas por la Comisión y Subcomisiones encargadas del estudio del Proyecto de Nueva Constitución Política de la República (Santiago de Chile, Imprenta Universitaria).

Oficina de Informaciones de la Cámara de Diputados de Chile, Sección Estadísticas (2014): Boletín Estadístico año 2013 (disponible en www.cámara.cl).

Proyecto de Modernización-Congreso Nacional Chile (1994): Proceso legislativo chileno. Un enfoque cuantitativo. La transición democrática 1990-1994 (s/e, s/l). 